\title{
Tuning and Timing in Mammalian Type I Hair Cells and Calyceal Synapses
}

\author{
Jocelyn E. Songer ${ }^{1,3}$ and Ruth Anne Eatock ${ }^{1,2,3}$ \\ ${ }^{1}$ Department of Otology and Laryngology, Harvard Medical School, Boston, Massachusetts 02115, 2Department of Neurobiology, Harvard Medical School, \\ Boston, Massachusetts 02115, and ${ }^{3}$ Eaton-Peabody Laboratories, Massachusetts Eye and Ear Infirmary, Boston, Massachusetts 02114
}

\begin{abstract}
Afferent nerve fibers in the central zones of vestibular epithelia form calyceal endings around type I hair cells and have phasic response properties that emphasize fast head motions. We investigated how stages from hair-cell transduction to calyceal spiking contribute tuning and timing to central (striolar)-zone afferents of the rat saccular epithelium. In an excised preparation, we deflected individual hair bundles with rigid probes driven with steps and sinusoids $(0.5-500 \mathrm{~Hz})$ and recorded whole-cell responses from hair cells and calyces at room temperature and body temperature. In immature hair cells and calyces (postnatal days (P)1-P4), tuning sharpened at each stage. Transducer adaptation and membrane-charging time produced bandpass filtering of the receptor potential with best frequencies of $10-30 \mathrm{~Hz}$ and phase leads below $10 \mathrm{~Hz}$. For small stimuli, electrical resonances sharply tuned the hair-cell membrane in the frequency range of 5-40 Hz. The synaptic delay of quantal transmission added a phase lag at frequencies above $10 \mathrm{~Hz}$. The influence of spike thresholds at the calyceal spike initiation stage sharpened tuning and advanced response phase. Two additional mechanisms strongly advanced response phase above $10 \mathrm{~Hz}$ when present: (1) maturing (P7-P9) type I hair cells acquired low-voltage-activated channels that shortened the rise time of the receptor potential and (2) some calyces had nonquantal transmission with little synaptic delay. By reducing response time, the identified inner-ear mechanisms (transducer adaptation, low-voltage-activated channels, nonquantal transmission, and spike triggering) may compensate for transmission delays in vestibular reflex pathways and help stabilize posture and gaze during rapid head motions.
\end{abstract}

\section{Introduction}

Primary afferents form large calyceal endings on type I hair cells of amniote vestibular epithelia. The calyces contrast with compact bouton endings formed on most hair cells and are the only reported postsynaptic neuronal calyces. Information on how this unique arrangement works is fragmentary and its contribution to vestibular signaling is not understood (for review, see Eatock and Songer, 2011). Here we follow the mechanosensory signal from the hair cell to the afferent calyx in a semi-intact preparation of the immature rat saccular epithelium, addressing the impacts of transduction, voltage-gated channels, the synapse, and afferent spike generation on stimulus processing.

We focus on hair cells and calyceal endings in a central swath within the epithelium (the striola), which differs from the surrounding extrastriola, especially in the activities of innervating

\footnotetext{
Received Aug. 24, 2012; revised Dec. 21, 2012; accepted Jan. 3, 2013.

Author contributions: J.E.S. and R.A.E. designed research; J.E.S. and R.A.E. performed research; J.E.S. contributed unpublished reagents/analytic tools; J.E.S. and R.A.E. analyzed data; J.E.S. and R.A.E. wrote the paper.

This study was supported by National Institutes of Health (R01 DC002290 and American Recovery \& Reinvestment Act supplement) and National Space Biomedical Research Institute through National Aeronautics and Space Administration NCC 9-58 (J.E.S.). We thank Ben Winterroth, Tilly Kimm, Alison Casserly, and the Engineering Group at Eaton-Peabody Laboratories for technical assistance, and Dianna Sands and Jess Cunha for administrative assistance. We thank Drs. John Guinan, Radha Kalluri, and Dan Merfeld for helpful comments on an earlier version of this manuscript.

The authors declare no competing financial interests.

Correspondence should be addressed to Dr. Ruth Anne Eatock, Eaton-Peabody Laboratories, Massachusetts Eye and Ear Infirmary, 243 Charles Street, Boston, MA 02114. E-mail: eatock@meei.harvard.edu.

DOI:10.1523/JNEUROSCI.4067-12.2013

Copyright $\odot 2013$ the authors $\quad 0270-6474 / 13 / 333706-19 \$ 15.00 / 0$
}

nerve fibers (for review, see Goldberg, 1991; Eatock and Songer, 2011). These differences closely parallel differences between central and peripheral zones of semicircular canal epithelia. Striolar and central-zone afferents are larger than extrastriolar and peripheral-zone afferents, with greater conduction speeds (Goldberg and Fernández, 1977; Lysakowski et al., 1995) and more phasic (adapting) response dynamics (Baird et al., 1988; Goldberg et al., 1990a; Hullar et al., 2005). Type I cells and calyces occur in both zones, but are larger and more specialized in striolar and central zones (Baird et al., 1988; Goldberg et al., 1990a), where they often enclose two or more type I hair cells, each with as many as 50 presynaptic ribbons (Lysakowski and Goldberg, 1997). With their accessible sensory receptors, large synapses, and known functions, vestibular epithelia are appropriate models for neurobiological specializations for timing and tuning.

As an approximately vertical linear accelerometer with a broad frequency range, the mammalian saccule detects head tilt, voluntary and passive vertical head motions, bone vibrations, and loud sounds (McCue and Guinan, 1994; Curthoys and Vulovic, 2011). To study vestibular afferent responses to head motions, investigators often move the head sinusoidally at low frequencies (upper limit, 2-30 Hz). By delivering sinusoidal stimuli directly to the hair bundle, we were able to increase the upper frequency limit for a fuller characterization of hair-cell and afferent tuning. To provide time-domain results for comparison with the hair-cell literature, we also applied steps of bundle displacement, voltage, or current, with rise times far shorter than possible in vivo. To investigate the impact of synaptic transmis- 


\section{A Saccular macula}

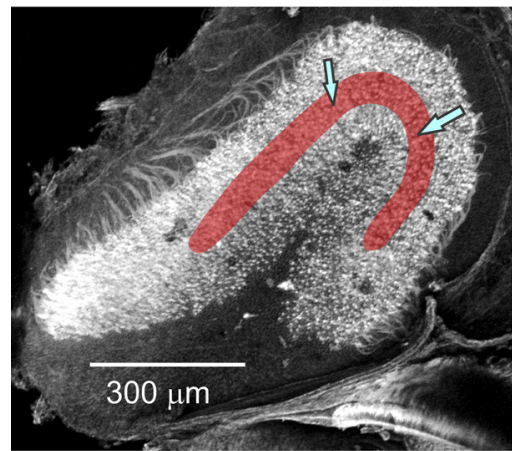

B

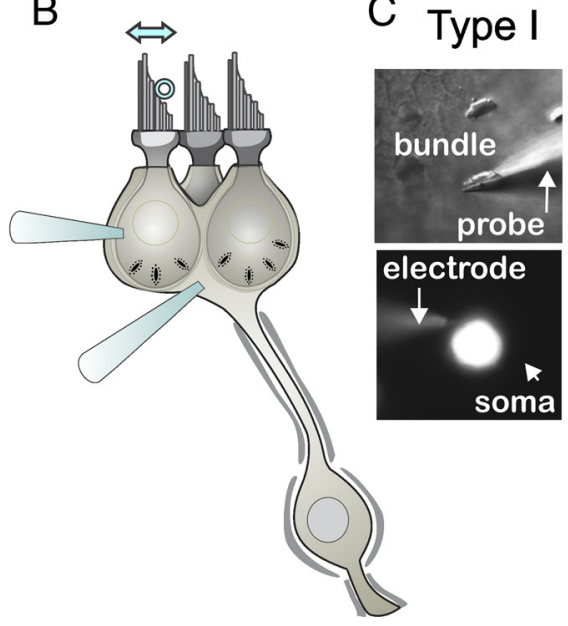

D Triple calyx

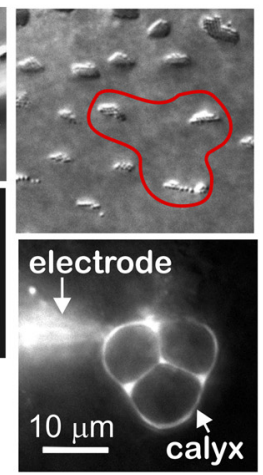

Figure 1. Recording from hair cells and calyceal afferent terminals in the rat saccular epithelium. $A$, Confocal image of the saccular epithelium excised from a P2 rat (modified from Fig. 2 C in Eatock and Songer, 2011). The striolar zone is overlaid with red; most recordings were made from the region between the two blue arrows. The tissue was stained with phalloidin, which labels the actin-based hair bundles, with antibodies to $\beta 3$-tubulin, which labels all nerve fibers, and with calretinin, which labels type Il hair cells and calyx-only striolar nerve fibers. $\boldsymbol{B}$, $S$ chematic, illustrating a "triple" calyx around three type I hair cells, shows two recording electrodes, one on a hair cell and one on the calyx. Just one recording electrode was used at a time. A stimulus probe (open circle) was positioned against the staircase edge of the hair bundle to deflect it along its most sensitive axis (double arrow above bundle) while recordings were made in whole-cell patch-clamp mode from either the type I hair cell or its postsynaptic calyx. C, Stimulation and recording from a striolar type I hair cell, as viewed from above with differential-interference-contrast or fluorescence optics. Top, The hair bundle was deflected along its sensitive axis with a rigid glass probe. Bottom, The soma below the hair bundle, filled with fluorescent rhodamine diffused in from the recording pipette (electrode). Scale bar in $\boldsymbol{D}$ applies to $\boldsymbol{C}$. D, Recording from a triple calyx, as viewed from above. Top, The hair bundles of the three type I hair cells within the calyx are outlined (red). Bottom, The recording electrode has filled the triple calyx terminal with rhodamine.

sion on the afferent signal, we compared presynaptic (hair cell) and postsynaptic (calyceal) responses to similar stimuli. To reveal the effect of membrane electrical properties, we compared wholecell recordings of voltage and current to similar stimuli. These are the first reported recordings from mammalian saccular hair cells and from any mammalian vestibular hair cells at body temperature.

We report that in immature saccular epithelia, tuning and timing are strongly affected by transducer adaptation, membrane charging time, synaptic delay of quantal transmission, and spike triggering. Maturational changes in hair cells reduce the impact of membrane charging time. We also provide evidence for nonquantal transmission from type I hair cells to calyces.

\section{Materials and Methods}

Preparation. Animals were handled in accordance with the NIH Guide for the Care and Use of Laboratory Animals and all procedures were approved by the Animal Care Committee at the Massachusetts Eye and Ear Infirmary. Chemicals were obtained from Sigma-Aldrich unless otherwise specified.

Saccules were excised from male and female Long-Evans rats (Charles River), postnatal days (P) 1-P9. At these ages, before the eyes open and cochleas start working, the rat vestibular inner ear exhibits low sensitivity (Curthoys, 1983); it presumably contributes to the righting reflex. Preparation, stimulation, and recording methods resembled our previous descriptions for the rodent utricle (Vollrath and Eatock, 2003; Wooltorton et al., 2007). Briefly, the animal was decapitated and the temporal bone removed and immersed in our standard external solution: Leibovitz-15 (L-15) medium supplemented with 10 mм HEPES-NaOH, pH 7.35 $(\sim 315 \mathrm{mmol} / \mathrm{kg})$. The otic capsule was opened and the saccule plus attached vestibular nerve branches and ganglion were excised and bathed for $10-20 \mathrm{~min}$ in L-15 with $100 \mu \mathrm{g} / \mathrm{ml}$ of protease XXIV at ambient temperature $\left(\sim 25^{\circ} \mathrm{C}\right)$. The otolithic membrane was removed and the epithelium plus its innervating ganglion were mounted in an experimental chamber and held flat by glass fibers glued to a coverslip.

Zone and cell identification. We defined the striola as the zone of prominent complex calyces and large, widely spaced hair bundles (for a full description of the zones, see Eatock and Songer, 2011). In the utricular epithelium, the striola is medial to the line of polarity reversal of hair bundles (Li et al., 2008; Schweizer et al., 2009), but in the saccule it straddles the line of polarity reversal (J. E. Songer and R. A. Eatock, unpublished observations). To avoid mixing striolar and medial extrastriolar data, we focused on striolar cells located within 2 cell widths of the line of polarity reversal. Most recordings were from the area between blue arrows in Figure $1 A$. Type I hair cells were distinguished from type II cells by their calyces (Fig. $1 B, D$ ) and their larger hair bundles (Li et al., 2008). Most calyces in our dataset were complex, meaning that they contacted 2-4 type I hair cells; a triple calyx, around three hair cells, is schematized in Figure $1 B$ and shown in Figure $1 D$. By filling the calyces with a fluorescent dye in the pipette solution, we were able to determine the number of type I cells enveloped by the calyx, the extent of local branching, and whether the calyx-bearing afferent also made bouton terminals. No evidence for boutons was seen in 17 of 19 filled complex calyces, consistent with expectations based on an anatomical demonstration that virtually all complex calyces belonged to "calyx-only" afferents (Li et al., 2008). The two remaining calyces extended small processes that may or may not have formed nearby boutons. Because these calyces were not extraordinary in terms of their physiology, the data have been pooled. Calyces can also receive synaptic input from adjacent type II hair cells via "outerface" synapses, but we were only able to evoke calyceal activity by moving hair bundles of type I cells within the calyx, suggesting that the striolar calyces we studied were not receiving significant functional input from outer-face synapses with type II cells. This is consistent with quantitative estimates from another rodent vestibular organ, the chinchilla crista, that such outer-face synapses are rare (Lysakowski and Goldberg, 1997).

We also recorded from some extrastriolar calyces, which were usually simple (surrounding a single type I cell) and $\geq 4$ cell widths from the line of bundle polarity reversal. In contrast to striolar calyces, fluorescent dye fills showed that the extrastriolar calyces we recorded from were simple calyces connected to afferent processes that branched extensively.

Recordings. Recordings were usually performed at bath temperatures between 25 and $29^{\circ} \mathrm{C}$ (mean $\sim 27^{\circ} \mathrm{C}$ ). In some experiments, we maintained bath temperature at $35-39^{\circ} \mathrm{C}\left(\right.$ mean $\left.\sim 37^{\circ} \mathrm{C}\right)$ with a heated platform and temperature controller (TC-344B, Warner Instruments). The standard internal solution contained (in $\mathrm{mM}$ ) the following: $135 \mathrm{KCl}, 0.1$ $\mathrm{CaCl}_{2}, 3.5 \mathrm{MgCl}_{2}, 3 \mathrm{Na}_{2} \mathrm{ATP}, 5$ creatine phosphate (Na salt), $0.1 \mathrm{Na}-$ cAMP, 0.1 Li-GTP, 5 EGTA, and 5 HEPES. The solution was brought to 
pH 7.3 and $\sim 300 \mathrm{mmol} / \mathrm{kg}$ by adding $\sim 28 \mathrm{~mm} \mathrm{KOH}$. We added the fluorescent dye, rhodamine (sulforhodamine $101,1 \mathrm{mg} / 100 \mathrm{ml}$; Invitrogen) to the standard internal solution to label the recorded hair cell or calyx (Fig. $1 C, D$ ). In some experiments, a modified internal solution with $10 \mathrm{~mm}$ HEPES and $130 \mathrm{~mm} \mathrm{KCl}$ was used. Because no differences were observed between cells recorded with the different internal solutions, the datasets have been pooled.

Recording pipettes were pulled from R-6 glass (Garner Glass) and had resistances ranging from 3 to $6 \mathrm{M} \Omega$ in our standard solutions. Currents or voltages were recorded in the ruptured-patch whole-cell mode with the EPC-10 amplifier with an integrated interface (HEKA), controlled by Patchmaster software (HEKA). Currents were low-pass-filtered with an integrated four-pole Bessel filter (HEKA) set at $2.9 \mathrm{kHz}$. Potentials are corrected for a liquid junction potential of $5 \mathrm{mV}$, calculated with JPCalc software (Barry, 1994). Hair cells and calyces were held at $-65 \mathrm{mV}$ for voltage-clamp recordings and at resting (zero-current) potential for current-clamp recordings unless otherwise noted. Capacitive currents were electronically nulled with Patchmaster controls.

Mechanical stimulation of the hair bundle. A stiff glass probe (tip diameter, $\sim 1 \mu \mathrm{m}$ ) was glued onto a one-dimensional piezoelectric bimorph element (Corey and Hudspeth, 1980), driven with voltages controlled by Patchmaster software and low-pass-filtered with an eight-pole Bessel filter (Frequency Devices). The probe was positioned approximately half-way up the staircase side of the bundle and oriented perpendicular to the axis of maximum sensitivity (Fig. $1 B, C$ ). Motions along the sensitive axis and toward the tall edge of the bundle are called "positive." For typical stimuli ( $\leq \pm 1 \mu \mathrm{m})$, coupling in both directions appeared good based on visual evaluation as well as response speed. The bimorph was driven with step waveforms [rise time, $<800 \mu \mathrm{s}$; duration, $400 \mathrm{~ms}$; lowpass filtered at $1 \mathrm{kHz}$ with an 8-pole Bessel filter (Model 902, Frequency Devices)] or a series of sinusoidal "bursts" (as in tone burst) of five cycles each (low-pass filtered at $1.8 \mathrm{kHz}$ with the 8-pole Bessel filter). The frequencies of stimulation were typically $2,5,10,20,40,50,80$, and 100 $\mathrm{Hz}$, but in some cases extended down to $0.5 \mathrm{~Hz}$ and up to 200 or $500 \mathrm{~Hz}$. Sinusoidal displacements were centered at or near the resting bundle position and had amplitudes of either $\pm 300 \mathrm{~nm}$ or between \pm 600 and $\pm 1000 \mathrm{~nm}$; data collected with stimuli in this larger range, toward the saturating end of the hair cell's operating range (Fig. 2C; see Results), have been pooled. We calibrated probe displacement at both stimulus levels and across all frequencies by projecting the probe image onto the edge of a photodiode. The photodiode output was low-pass filtered at $1800 \mathrm{~Hz}$ and digitized at $100 \mu \mathrm{s}$. The stimulus probe had a voltage sensitivity of $350 \mathrm{~nm} / \mathrm{V}$ and a mechanical resonance near $3 \mathrm{kHz}, 10$-fold above the stimulus frequencies analyzed here. Bode analysis of the photodiode signals showed that the probe motion had stable gain (to within $15 \mathrm{~nm}$ ) and its phase angle was within $1-2^{\circ}$ of the driving voltage from 2 to $100 \mathrm{~Hz}$. The stimulus gain and phase at each frequency and level were calibrated offline by the appropriate photodiode signal.

Analysis. Data were analyzed with Origin 8.1 software (Microcal Software). Results are presented as means \pm SEs of the mean. Significance was assessed with the two-tailed Student's $t$ test or ANOVA as implemented by Origin 8.1; all samples were tested for equal variance. Mechanically evoked responses were rejected if there was baseline drift during the measurement period or if the signal-to-noise ratio was small. Data were accepted if maximum values were $\geq 40 \mathrm{pA} / \mu \mathrm{m}$ for transduction currents $\left(I_{\text {met }}\right.$; noise floor, $\left.\leq 10 \mathrm{pA}\right) ; \geq 10 \mathrm{mV} / \mu \mathrm{m}$ for receptor potentials (RPs; noise floor, $\leq 1 \mathrm{mV}$ ) for immature cells and $\geq 3 \mathrm{mV} / \mu \mathrm{m}$ for more mature hair cells with a low-voltageactivated conductance that reduces receptor potential gain; $\geq 5$ $\mathrm{pA} / \mu \mathrm{m}$ for EPSCs (noise floor, $\leq 1 \mathrm{pA}$ ); $\geq 1 \mathrm{mV} / \mu \mathrm{m}$ for EPSPs (noise floor, $\leq 100 \mu \mathrm{V})$; and 5 spikes/s/ $\mu \mathrm{m}$ for spike rate. The recorded EPSCs and EPSPs may in some cases include both quantal (vesicular) responses and nonquantal responses (see Results; see Figure 5). Both responses, when present, will contribute to the fundamental $\left(f_{0}\right)$ component of the fast Fourier transforms (FFTs) that we plot in Bode plots. Pharmacological separation of quantal and nonquantal components was not done.

Membrane capacitance $\left(C_{\mathrm{m}}\right)$, membrane resistance $\left(R_{\mathrm{m}}\right)$, and series resistance $\left(R_{\mathrm{s}}\right)$ were calculated online by the Patchmaster soft- ware. Hair cell $C_{\mathrm{m}}$ was $7.9 \pm 0.2 \mathrm{pF}$ (38 cells) and did not clearly vary with age between $\mathrm{P} 1$ and $\mathrm{P} 9$. Uncompensated $R_{\mathrm{s}}$ was $16 \pm 1 \mathrm{M} \Omega$ (38 cells). Hair-cell input resistance varied with age because type I cells acquire a low-voltage-activated conductance as they mature (Rüsch et al., 1998; see Fig. 10). Capacitance estimates were made for a subset of the calyx data: $C_{\mathrm{m}}$ was $18 \pm 5 \mathrm{pF}$ for 10 double complex calyces (each envelopes 2 type I hair cells), $17 \pm 10 \mathrm{pF}$ for five triple complex calyces (enveloping three hair cells), and 4.3 and $5.8 \mathrm{pF}$ for two simple calyces, each contacting just one hair cell. In calyceal recordings, space clamp is not always achieved because of long attached afferent fibers, but Patchmaster estimates of the capacitive current are dominated by the fastest (proximate) component (i.e., the calyx).

$I(X)$ relations were made by plotting $I_{\text {met }}$ against bundle displacement $(X)$ either for positive-going half-cycles of a sinusoidal stimulus or for families of step displacements. The relations were fit with either a firstorder Boltzmann function:

$$
I(X)=\frac{I_{\max }}{1+e^{\left(x-x_{2}^{1}\right) / s}}
$$

where $I_{\max }$ is the maximum current (relative to the current at saturating negative displacements), $X_{1 / 2}$ is the displacement evoking a half-maximal response, and $S$ is the displacement corresponding to an $e$-fold rise in $I_{\text {met }}$ for $X<X_{1 / 2}$; or a second-order Boltzmann function:

$$
I(X)=\frac{I_{\max }}{\left(1+e^{A_{1}\left(P_{1}-X\right)\left(1+e^{A_{2}\left(P_{2}-X\right)}\right)}\right)}
$$

where $A_{1}$ and $A_{2}$ are constants that set the steepness of the second-order Boltzmann and $P_{1}$ and $P_{2}$ are constants that set its position on the $x$-axis. Equation 1 was used if Equation 2 did not improve the $R^{2}$ value. From such Boltzmann fits, we calculated the operating range (OR) as the range of displacements over which the response grew from $10 \%$ of $I_{\max }$ to $90 \%$ of $I_{\max }$.

Responses to positive step displacements were analyzed to provide the time course of adaptation. We fit the first $250 \mathrm{~ms}$ of the response (following the peak) with a double exponential function as shown in Equation 3:

$$
I(t)=A_{\text {first }} e^{-\frac{t}{\tau_{\text {sast }}}}+A_{\text {slow }} e^{-\frac{t}{\tau_{\text {slow }}}}+I_{\text {ss }}
$$

where $\tau_{\text {fast }}$ and $\tau_{\text {slow }}$ are the short and long time constants, $A_{\text {fast }}$ and $A_{\text {slow }}$ are the amplitudes of the exponential terms, and $I_{\mathrm{SS}}$ is the steady-state current. Goodness of fit was assessed from the coefficient of determination $\left(R^{2}\right.$ value $)$ and visual inspection of the fit. A double-exponential function fit to the decay during the half-maximal step $\left(X_{1 / 2}\right)$ yielded time constants that differed by an order of magnitude and provided a significantly better fit than a single-exponential function, as determined by eye and by a significantly improved $R^{2}$ value.

We quantified the extent of adaptation (percentage decay):

$$
\text { Extent of Adaptation }=\left(1-\frac{I_{\mathrm{SS}}-I_{\mathrm{o}}}{I_{\text {peak }}-I_{\mathrm{o}}}\right) \times 100
$$

where $I_{\mathrm{o}}, I_{\text {peak }}$, and $I_{\mathrm{ss}}$ are pre-step, peak, and adapted (steady-state) levels of the step-evoked current response at $X_{1 / 2}$.

Sinusoidal responses were analyzed with Matlab 7 (Matlab). To show frequency dependence in a way that can be compared with published afferent data from in vivo studies (Fernández and Goldberg, 1976; Goldberg et al., 1990b; Lasker et al., 2008), we plotted the gain and phase of the fundamental $\left(f_{0}\right)$ component of the response referenced to the $f_{0}$ component of the probe motion (Fig. 2E). FFTs were performed on hair-cell transduction currents $\left(I_{\text {met }}\right)$, RPs, EPSCs or EPSPs, and the photodiode monitor of stimulus-probe displacement.

In our study, striolar calyceal afferents typically had little to no background firing and spike rates (spikes/cycle or spikes/second) were obtained by counting spikes during sinusoidal bursts (sinusoidal bundle displacements of 5 cycles duration at a specific frequency). These spike rates were divided by the stimulus magnitude to generate transfer functions of either spikes/cycle/micrometer or spikes/second/micrometer. 
Since all spikes were stimulus-driven and also phase-locked over the stimulus frequency range, it was straightforward to determine the phase angle of each spike relative to stimulus phase. The resulting phase distributions were normal (data not shown), validating this simple method of determining phase. Average phases were reported in the Bode plots. More complex methods are needed when spontaneous rates are significant (Cherif et al., 2008).

Analysis of the voltage dependence of outwardly rectifying current in hair cells. Conductance-voltage $[G(V)$ or activation] curves were constructed from "tail currents," currents at the offset of each voltage step in an iterated voltage series. The voltage at the offset of the iterated steps was $-35 \mathrm{mV}$, chosen to minimize contributions from $\mathrm{HCN}$ (hyperpolarization-activated, cyclic nucleotide-gated cation) channels, which reverse near $-35 \mathrm{mV}$. To obtain conductance $(G)$, tail currents were divided by driving force $V_{\mathrm{m}}-V_{\text {rev }}$, where $V_{\text {rev }}$ is the reversal potential of the current. The outwardly rectifying conductance was assumed to comprise one or more $\mathrm{K}^{+}$conductance, for which $V_{\text {rev }}$ was approximated by the $\mathrm{K}^{+}$equilibrium potential $\left(E_{\mathrm{K}}=-84 \mathrm{mV}\right)$ calculated from $\mathrm{K}^{+}$concentrations in the bath and pipette solutions. The resulting sigmoidal curves were fit with a first-order Boltzmann function (Eq. 5):

$$
G(V)=\frac{g_{\min }-g_{\max }}{1+e^{\left(V-V_{2}^{1}\right) / S}}+g_{\max }
$$

where $g_{\min }$ and $g_{\max }$ are the minimum and maximum conductance, $V_{1 / 2}$ is the voltage of half-maximal activation, and $S$ is the voltage range producing an $e$-fold increase in current at voltages negative to $V_{1 / 2}$. Activation time course was estimated for voltage steps from -125 to $-35 \mathrm{mV}$ $\left(\sim V_{1 / 2}\right.$ of the outward current in immature type I hair cells) by fitting the data with the following equation:

$$
I(t)=I_{\mathrm{SS}}+I_{\mathrm{o}} e^{-t / \tau_{\mathrm{K}}}
$$

where $I_{\mathrm{SS}}$ and $I_{0}$ are the steady-state and initial current values and $\tau_{\mathrm{K}}$ is the activation time constant for the outward current. Activation of outwardly rectifying $\mathrm{K}^{+}$current in type I cells has previously been fit with more complex equations that introduce a brief delay at the onset (Rüsch and Eatock, 1996). However, the monoexponential Equation 6 provided a good fit to our hair-cell data, possibly because the initial stage of the response was obscured by large, transient, voltage-gated sodium $\left(\mathrm{Na}_{\mathrm{V}}\right)$ current.

Electrical resonance of immature type I hair cells was quantified by measuring the frequency and decay time of oscillatory voltage responses to depolarizing current steps. The electrical resonance frequency $\left(f_{\mathrm{e}}\right)$ was calculated by fitting a damped sinusoid to the voltage response beginning at the initial peak (Fig. 3A.1,D, F, for examples):

$$
V(t)=V_{\mathrm{SS}}+V_{\mathrm{p}} e^{-t / \tau_{e}} \sin \left(2 \pi f_{e} t-\theta\right)
$$

where $V_{\mathrm{SS}}$ is the steady-state voltage, $V_{\mathrm{p}}$ is the voltage of the peak response, $\tau_{\mathrm{e}}$ is the time constant for the decay of the envelope of the response, and $\theta$ is the phase angle. The quality, or sharpness, of electrical tuning was then defined as (Crawford and Fettiplace, 1981):

$$
Q_{e}=\left[\left(\pi f_{e} \tau_{e}\right)^{2}+0.25\right]^{\frac{1}{2}}
$$

\section{Results}

To show how processing in the hair cell and afferent terminal contributes to shaping afferent responses in both the time and frequency domains, we compare the signals evoked at each stage by deflecting the hair bundle (Fig. $1 B, C$ ) with step displacements (time domain) or with a series of sinusoidal bursts at frequencies incremented from 2 to $100 \mathrm{~Hz}$ (frequency domain). We present whole-cell voltage-clamp and current-clamp recordings from hair cells [transduction currents $\left(I_{\text {met }}\right)$ and receptor potentials (RPs)] and calyceal terminals (EPSCs, EPSPs, their nonquantal counterparts, and action potentials or spikes).
Most data were collected from striolar type I hair cells or calyces at room temperature $\left(25-29^{\circ} \mathrm{C}\right)$ between $\mathrm{P} 2$ and P9, an immature period in which rats lack sight or hearing but do have some vestibular function as shown by righting reflexes. We also show select data at mammalian temperatures (range, $35-39^{\circ} \mathrm{C}$ ). We conclude with data from type I hair cells in the second postnatal week which demonstrate the effects of electrophysiological maturation on the frequency dependence of the receptor potential.

\section{Transducer adaptation}

In multiple in vitro preparations (for review, see Eatock, 2000; Fettiplace and Hackney, 2006), hair cells adapt to sustained bundle deflections. We applied step bundle displacements to characterize the time course of adaptation in the rat saccular striola and its influence on the transducer operating range. We applied sine bursts to illustrate the effects of adaptation on frequency tuning and phase. We compare recordings at $25-29^{\circ} \mathrm{C}$ and $35-39^{\circ} \mathrm{C}$ to show the temperature dependence of some properties of transduction and adaptation. These results are summarized in Figure 2 and Table 1.

\section{Step-evoked adaptation}

In Figure $2 A$, the hair bundle of a striolar type I hair cell was deflected by a rigid probe in a $36^{\circ} \mathrm{C}$ bath. Step displacements in the positive direction evoked currents $\left(I_{\text {met }}\right)$ that rose rapidly and then adapted (decayed) with two time constants, $\tau_{\text {fast }}$ and $\tau_{\text {slow }}$ (Eq. 3), differing by approximately an order of magnitude (Fig. $2 A$, inset; Table 1$)$. Figure $2 B$ shows average parameters from exponential fits (Eq. 3) to adapting step responses of six cells at $25-29^{\circ} \mathrm{C}$ (designated in figures by the average value, $27^{\circ} \mathrm{C}$ ) and seven other cells at $35-39^{\circ} \mathrm{C}\left(\right.$ designated $\left.37^{\circ} \mathrm{C}\right) . \tau_{\text {fast }}$ and $\tau_{\text {slow }}$ (Fig. $2 \mathrm{B.1}$ ), the relative proportions of fast and slow components (Fig. 2B.2), and percentage decay (extent of adaptation, Fig. 2 B.3) all changed with stimulus level. While some differences were noted with temperature (next paragraph), trends with stimulus level were similar at the two temperatures. For the smallest displacements $(+100 \mathrm{~nm}), \tau_{\text {fast }}$ and $\tau_{\text {slow }}$ averaged $\sim 2$ and $40 \mathrm{~ms}$ at $35-$ $39^{\circ} \mathrm{C}$ and the fast component dominated, producing $\sim 75 \%$ of the total decay. As stimulus level ( $X$, displacement) increased, both time constants increased twofold and the proportion of slow component (Eq. 3, Fig. 2 B.2) increased to over $\sim 60 \%$ at $X>1$ $\mu \mathrm{m}$. The extent of adaptation (Fig. 2 B.3) also varied with level, decreasing from $\sim 85 \%$ at $100 \mathrm{~nm}$ to $\sim 65 \%$ at $1 \mu \mathrm{m}\left(35-39^{\circ} \mathrm{C}\right)$. Table 1 provides average parameters of adaptation at the midpoint $\left(X_{1 / 2}\right)$ of the peak operating range. At both temperatures, $I_{\text {met }}$ adapted to a steady-state value of $\sim 20 \%$ of the peak $(\sim 80 \%$ decay) via fast and slow components, each contributing $40-60 \%$ of the total decay and with mean time constants approximately one order of magnitude apart $(\sim 4-5$ and $\sim 60 \mathrm{~ms})$. These immature saccular hair cells behave similarly to mouse utricular hair cells (Géléoc and Holt, 2003; Vollrath and Eatock, 2003).

\section{Temperature effects}

At $35-39^{\circ} \mathrm{C}$, the fast component of adaptation was slightly but significantly faster (Fig. 2 B.1; 2-way ANOVA, $p<0.05$ for temperature and level): mean $\tau_{\text {fast }}$ values of $4.7 \mathrm{~ms}$ (averaged across all levels) at $25-29^{\circ} \mathrm{C}$ and $3.6 \mathrm{~ms}$ at $35-39^{\circ} \mathrm{C}$ yield a thermal coefficient of 1.3. The extent of adaptation (percentage decay; Fig. 2 B.3) decreased with increasing temperature (2-way ANOVA, $p<1.5 \mathrm{e}-7$ for both temperature and level). Pooling the data across 11 displacements, the mean steady-state extent of adaptation (Eq. 4) was $77 \pm 2 \%$ at $25-29^{\circ} \mathrm{C}$ and $69 \pm 2 \%$ at $35-39^{\circ} \mathrm{C}$, for a thermal coefficient of 1.12 . 
A I ${ }_{\text {met }}$ steps $\mathrm{P} 136^{\circ} \mathrm{C}$
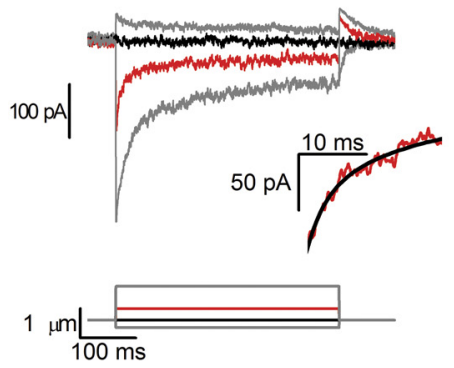

D I ${ }_{\text {met }}$ sinusoidal bursts $\mathrm{P} 136^{\circ} \mathrm{C}$

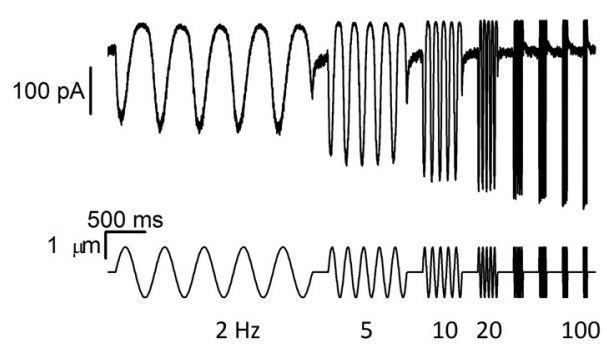

B Adaptation

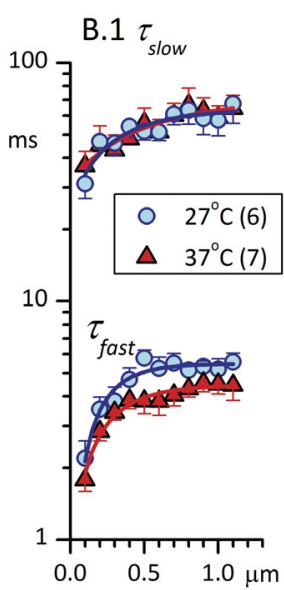

\section{E FFT}
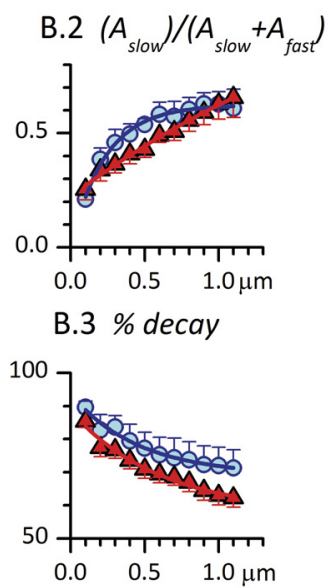

C $\mathrm{I}(\mathrm{X})$ relations

\section{1 steps $37^{\circ} \mathrm{C} 27^{\circ} \mathrm{C} \quad$ C. 2 sines $37^{\circ} \mathrm{C}$}
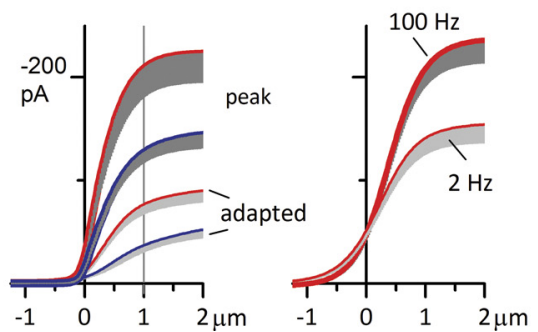

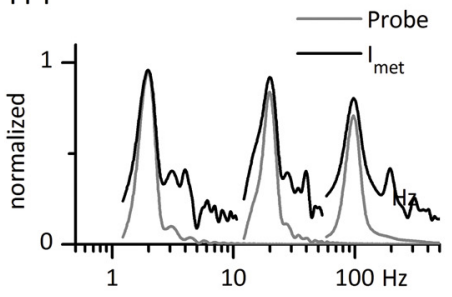

F I ${ }_{\text {met }}$ gain and phase

$27^{\circ} \mathrm{C} 37^{\circ} \mathrm{C}$

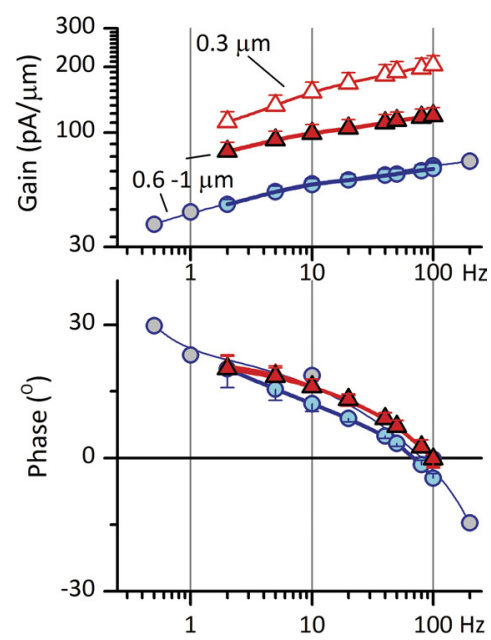

Figure 2. Effects of adaptation and temperature on sensitivity (gain) and timing (phase) of $I_{\text {met }}$. Data were collected in two temperature ranges: $25-29^{\circ} \mathrm{C}$ (blue symbols) and $35-39^{\circ} \mathrm{C}$ (red symbols). For pooled data, we abbreviate these ranges to their

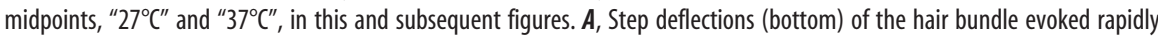
adapting transduction currents in a P1 striolar type I hair cell at $36^{\circ} \mathrm{C}$. Red trace, The response to a step at the midpoint of the operating range, $X_{1 / 2}$. Inset, The first $20 \mathrm{~ms}$ following the step to $X_{1 / 2}$. Black curve, Double-exponential fit (Eq. $3 ; \tau_{\text {fast }}=2.7 \mathrm{~ms}$, $\left.\tau_{\text {slow }}=15.9 \mathrm{~ms}, I_{\mathrm{ss}}=-51 \mathrm{pA}, A_{\text {slow }}=-49 \mathrm{pA}, A_{\text {fast }}=-72 \mathrm{pA}\right) . \boldsymbol{B}$, Parameters of adaptation as functions of hair-bundle displacement, at two different temperature ranges. Averages for six striolar type I hair cells at $27^{\circ} \mathrm{C}$ and seven striolar type Ihair cells at $37^{\circ}$ C. B.1, Fast and slow time constants from double-exponential fits (Eq. 3; fit shown in $\boldsymbol{A}$, black curve, inset). $\tau_{\text {fast }}$ values were significantly faster at $37^{\circ} \mathrm{C} . \boldsymbol{B . 2}$, The relative importance of slow adaptation increased with bundle displacement. The amplitude of the slow adaptation term $\left(A_{\text {slow' }}\right.$ Eq. 3$)$ is divided by the sum of the amplitudes of the fast and slow terms and plotted against bundle displacement. This fraction increased similarly with level at both temperatures; slow adaptation accounted for $20 \%$ of the adaptation (decay) at the smallest displacements and $60-70 \%$ at the largest displacements. B.3, Percentage decay (extent of adaptation, Eq. 4) at steady state, as estimated by the double-exponential fits, decreased with displacement, and was smaller at every displacement at $37^{\circ} \mathrm{C}$ than at $27^{\circ} \mathrm{C}$. C, Effects of adaptation and temperature on $/(X)$ relations. Averaged $I(X)$ relations were derived from steps ( $(\boldsymbol{C}$.1, same cells as in $\boldsymbol{B})$ and sinusoidal burst data $(\boldsymbol{C . 2})$. Step data $(\boldsymbol{C} . \mathbf{1}): /(X)$ relations for peak and steady-state currents were fit with Equation 2 and averaged to produce mean and SEM values (gray shading, -1 SEM) (see Table 1 for fit values). Thick lines with dark shading, Peak (onset) $I_{\text {met }}$. Thin lines with light shading, Adapted (steady state) responses. Sinusoidal burst data (C.2, same axes): I(X) relations were point-by-point plots of $I_{\text {met }}$ against $X$ for the rising half-cycle of the sinusoidal burst, averaged across all five cycles in the burst. Shown are mean - SEM values of first-order Boltzmann fits (Eq. 1) for $100 \mathrm{~Hz}$ fits (thick line, $n=12$ ) and $2 \mathrm{~Hz}$ fits (thin line, $n=10$ ) at $35-39^{\circ} \mathrm{C}$; see Table 1 for fit values. $\boldsymbol{D}, I_{\text {met }}$ (top, average of 5 traces) from the same P1 striolar type I hair cell as in $A$, evoked by $\pm 1 \mu \mathrm{m}$ sinusoidal bundle displacements $\left(2-100 \mathrm{~Hz}\right.$, bottom), $36^{\circ} \mathrm{C}$. Adaptation caused high-pass filtering (attenuation of the response at low frequencies). $\boldsymbol{E}$, Representative FFT analyses of $I_{\text {met }}$ (dark gray, $27^{\circ} \mathrm{C}$ ) and probe motion (light gray) produced by $\pm 1 \mu \mathrm{m}$ sinusoidal bursts at 2 (left), 20 (middle), and $100 \mathrm{~Hz}$ (right). Higher harmonics
Effects of adaptation and temperature on $\mathrm{I}(\mathrm{X})$ relations

Adaptation's effects on the relationship between $I_{\text {met }}$ and bundle deflection are summarized in Figure 2C. Figure 2C.1 compares, for the same cell sample of Figure $2 B$, averaged $I(X)$ relations from peak and steady-state responses to $400 \mathrm{~ms}$ displacement steps at $25-29^{\circ} \mathrm{C}$ [mean (blue) - SE (gray), 6 cells] and $35-39^{\circ} \mathrm{C}$ (red, 7 cells, different from the sample at $25-29^{\circ} \mathrm{C}$ ). These relations were better fit by a second-order Boltzmann function (Eq. 2) than by a first-order Boltzmann function (Eq. 1), consistent with more than one closed state for the transduction channels. Table 1 gives averaged parameter values from fits of Equation 2, yielding estimates of maximal current $\left(I_{\max }\right), X_{1 / 2}$, open probability at the resting bundle position $\left(P_{\mathrm{o}}\right)$, and OR. Increasing temperature by $10^{\circ} \mathrm{C}$ increased both peak and steady-state current 1.5-1.6-fold. Steadystate $I_{\max }$ was $\sim 40 \%$ of peak $I_{\max }$ at both temperatures.

\section{Adaptation's effects in the}

frequency domain

To study the frequency dependence of $I_{\text {met }}$, we delivered a series of sinusoidal bundle displacements in bursts of five cycles each, typically incremented from 2 to $100 \mathrm{~Hz}$. Displacements were $\pm 600-1000$ $\mathrm{nm}$ or, less frequently, $\pm 300 \mathrm{~nm}$.

$I_{\text {met }}$ increased with stimulus frequency (Fig. 2D): this high-pass filtering is attributable to transducer adaptation, which reduces responses at low frequencies. To quantify the effect across multiple hair cells and to also determine phase (timing) as a function of frequency, we generated Bode plots of the fundamental $\left(f_{0}\right)$ component of $I_{\text {met }}$ relative to the stimulus from FFTs (see Materials and Methods). Figure $2 E$ illustrates FFTs of $I_{\text {met }}$ from a striolar type I hair cell during $\pm 600 \mathrm{~nm}$ sinusoidal bursts at 2, 20, and $100 \mathrm{~Hz}$, plus FFTs of the corresponding probe motion as monitored by a photodiode (see Materials and Methods). For each burst frequency, the probe motion had one major

$\left(2 f_{0}\right.$ and $\left.3 f_{0}\right)$ are at least $15 \mathrm{~dB}$ below the $f_{0}$ peak. $\boldsymbol{F}$, Bode plots of the average gain (top) and phase angle (bottom) of the fundamental $\left(f_{0}\right)$ component of $I_{\text {met }}$ for 27 and $37^{\circ} \mathrm{C}$ in response to large stimuli $( \pm 0.6-1 \mu \mathrm{m})$. Responses are also plotted for a smaller stimulus $( \pm 0.3 \mu \mathrm{m})$ at $37^{\circ} \mathrm{C}$. Positive phase angles at low stimulus frequencies and increasing gain with increasing frequency are attributable to adaptation of $I_{\text {met }}$ Gains and phase leads were higher for both stimulus levels at $37^{\circ} \mathrm{C}$ (red) than at $27^{\circ} \mathrm{C}$ (blue); see Table 1 for average values and $n$ 's in each condition. Gray circles, Responses of one cell $\left(27^{\circ} \mathrm{C}\right)$ to an extended frequency range. 
Table 1. Temperature dependence of transducer $I(X)$ relations and adaptation

\begin{tabular}{|c|c|c|c|c|c|c|c|c|c|}
\hline \multirow[t]{2}{*}{ Temperature } & \multicolumn{5}{|l|}{$I(X)$ parameters } & \multicolumn{4}{|c|}{ Adaptation at $X_{1 / 2}$} \\
\hline & Stimulus $(n)$ & $I_{\max }, \mathrm{pA}$ & $\mathrm{OR}, \mathrm{nm}$ & $P_{0}$ & $X_{1 / 2}, \mathrm{~nm}$ & $\tau_{\text {fast }}, \mathrm{ms}$ & $\tau_{\text {slow }}, \mathrm{ms}$ & Percent decay & Percent $A_{\text {slow }}$ \\
\hline \multirow[t]{6}{*}{$27^{\circ} \mathrm{C}$} & Step & & & & & & & & \\
\hline & Peak (6) & $148 \pm 14$ & $1221 \pm 161$ & $0.12 \pm 0.02$ & $374 \pm 45$ & $4.7 \pm 0.7$ & $56 \pm 9$ & $79 \pm 5$ & $45 \pm 4$ \\
\hline & Steady-state (6) & $58 \pm 10$ & $1403 \pm 247$ & $0.12 \pm 0.04$ & $634 \pm 172$ & & & & \\
\hline & $0.6-1 \mu \mathrm{m}$ Sine & & & & & & & & \\
\hline & $100 \mathrm{~Hz}$ (13) & $144 \pm 12$ & $1056 \pm 97$ & $0.16 \pm 0.03$ & $405 \pm 43$ & & & & \\
\hline & $2 \mathrm{~Hz}(12)$ & $96 \pm 6$ & $1263 \pm 66$ & $0.51 \pm 0.05$ & $-20 \pm 55$ & & & & \\
\hline \multirow[t]{6}{*}{$37^{\circ} \mathrm{C}$} & Step & & & & & & & & \\
\hline & Peak (7) & $\begin{array}{c}233 \pm 30 \\
p<0.03^{a}\end{array}$ & $902 \pm 58$ & $0.13 \pm 0.02$ & $311 \pm 23$ & $3.6 \pm 0.2^{b}$ & $58 \pm 6$ & $77 \pm 3$ & $36 \pm 4$ \\
\hline & Steady-state (7) & $\begin{array}{l}94 \pm 15 \\
p<0.001^{c}\end{array}$ & $1244 \pm 152$ & $0.13 \pm 0.03$ & $437 \pm 26$ & & & & \\
\hline & $0.6-1 \mu \mathrm{m}$ Sine & & & & & & & & \\
\hline & $100 \mathrm{~Hz}(12)$ & $\begin{aligned} 241 & \pm 25 \\
p & <0.001^{d}\end{aligned}$ & $1178 \pm 59$ & $0.22 \pm 0.03$ & $348 \pm 42$ & & & & \\
\hline & $2 \mathrm{~Hz}(10)$ & $\begin{aligned} 155 & \pm 18 \\
p & <0.003^{e}\end{aligned}$ & $1394 \pm 129$ & $\begin{array}{c}0.34 \pm 0.05 \\
p<0.03\end{array}$ & $\begin{aligned} 213 & \pm 69 \\
p & <0.02\end{aligned}$ & & & & \\
\hline
\end{tabular}

Maximum current $\left(I_{\max }\right)$ values ${ }^{\text {a,c,d,e }}$ were larger at $35-39^{\circ} \mathrm{C}$ (represented by the midpoint " $\left.37^{\circ} \mathrm{C}^{\prime \prime}\right)$ than at $25-29^{\circ} \mathrm{C}\left({ }^{\prime \prime} 27^{\circ} \mathrm{C}\right.$ "). Fast adaptation time constants ${ }^{\mathrm{b}}$ were slightly but significantly faster at $37^{\circ} \mathrm{C}$ when tested across all step displacements (2-way ANOVA).n, number of cells. OR, operating range. $P_{0}$, fraction of $I_{\text {met }}$ activated at $X=0 \mathrm{~nm}$. $X_{1 / 2}$, midpoint of sigmoidal fit to $/(X)$ relation. $\tau_{\text {fast }} \tau_{\text {slowe }}$ fast and slow adaptation time constants. Percent $A_{\text {slow }}$, percent of decay attributable to slow adaptation term.

peak at $f_{0}$. $I_{\text {met }}$ also had a large peak at $f_{0}$, plus smaller peaks at higher harmonics $\left(2 f_{0}\right.$ and $\left.3 f_{0}\right)$, which reflect nonlinearities in transduction. Nevertheless, the largest harmonic $\left(2 f_{0}\right)$ was at least $15 \mathrm{~dB}$ smaller than the $f_{0}$ component, indicating that Bode plots of the $f_{0}$ component capture much of the frequency dependence of $I_{\text {met }}$.

The Bode plots in Figure $2 \mathrm{~F}$ show how average gain $(\mathrm{pA} / \mu \mathrm{m})$ and phase of the $f_{0}$ component of $I_{\text {met }}$ varied with sinusoidal burst frequency at different stimulus levels and temperatures. At each frequency, the magnitude of the $f_{0}$ component of $I_{\text {met }}$ was divided by the magnitude of the $f_{0}$ component of the stimulus, and the phase of the response was referenced to the phase of the stimulus. Positive phase angles correspond to responses that lead the stimulus; negative phase angles correspond to responses that lag the stimulus. For cells held at $35-39^{\circ} \mathrm{C}$, responses were measured at two stimulus levels (filled red triangles, $\pm 600-1000 \mathrm{~nm}$; open red triangles, $\pm 300 \mathrm{~nm})$. At $25-29^{\circ} \mathrm{C}$, responses were obtained at one stimulus level ( $\pm 600-1000 \mathrm{~nm}$ ) averaged across multiple cells for $2-100 \mathrm{~Hz}$ (blue circles) and from one cell from $0.5-200 \mathrm{~Hz}$ (gray circles). In all cases, as stimulus frequency increased, $I_{\text {met }}$ increased and response phase decreased, from a lead of $\sim 20^{\circ}$ at 2 $\mathrm{Hz}$ to $0^{\circ}$ (in phase) at $\sim 100 \mathrm{~Hz}$.

When stimulus level was changed from $\pm 600-1000$ to \pm 300 $\mathrm{nm}$, response gain increased at all frequencies (compare filled and open red triangles). This is expected based on the nonlinear $I(X)$ relations of the hair cells, for which $+300 \mathrm{~nm}$ is below $X_{1 / 2}$ and $+600-1000 \mathrm{~nm}$ approaches or reaches positive saturation (Fig. 2C). The phase of $I_{\text {met }}$ relative to the stimulus was relatively insensitive to level in this range (Fig. $2 \mathrm{~F}$, bottom; points for different levels overlap in the phase plot).

Increasing temperature increased gain across all frequencies (Fig. $2 \mathrm{~F}$, compare filled blue circles and filled red triangles, same stimulus level), consistent with the temperature effect on $I_{\max }$ (Fig. 2C.1, Table 1). Increasing temperature also slightly increased phase leads (Fig. $2 \mathrm{~F}$, bottom): the mean phase angle across all frequencies was significantly larger at $37^{\circ} \mathrm{C}\left(11.7 \pm 0.9^{\circ}\right.$, $n=96)$ than at $27^{\circ}\left(8.5 \pm 1.0^{\circ}, n=80 ; p=0.0004,2\right.$-way ANOVA for temperature and stimulus frequency, with Bonferroni's and Tukey's post hoc corrections for multiple comparisons). This phase advance with temperature is consistent with the faster fast adaptation at high temperature (Fig. 2 B.1) and may also reflect faster channel activation. The decline in $I_{\text {met }}$ phase with frequency may reflect both a phase lead from transducer adaptation at low frequencies and a phase lag from transducer activation at high frequencies. For comparison, the transducer activation time constants of $\sim 1 \mathrm{~ms}$ in the turtle cochlea (Ricci et al., 2005) would produce significant phase lag above $100 \mathrm{~Hz}$.

The effect of transducer adaptation on sensitivity is illustrated in a different way in Figure 2C.2, with average $I(X)$ relations derived from $100 \mathrm{~Hz}$ sinusoidal bursts and $2 \mathrm{~Hz}$ sinusoidal bursts at $35-39^{\circ} \mathrm{C}$. In contrast to step-evoked $I(X)$ relations, $I(X)$ relations evoked by sinusoidal bursts were well fit by simple firstorder Boltzmann functions (Eq. 1), consistent with just two kinetic states (closed and open), and had larger $P_{\mathrm{o}}$ values. $I_{\max }$ values and ORs were similar for the $100 \mathrm{~Hz} I(X)$ relation and the peak step-evoked $I(X)$ relation (Fig. 2C.1, Table 1), indicating that at $100 \mathrm{~Hz}, I_{\text {met }}$ was not adapted. At $2 \mathrm{~Hz}, I_{\text {met }}$ was significantly but not fully adapted, as shown by comparison with steady-state $I(X)$ relations from step stimuli in Figure 2C.1.

In summary, at stimulus frequencies $<100 \mathrm{~Hz}$, high-pass filtering by adaptation attenuated responses and introduced a phase lead. Recordings at body temperature yielded larger $I_{\text {met }}$ values and therefore larger gains across all frequencies. The higher temperature also increased high-frequency phase leads, possibly as a combined effect of faster fast adaptation and faster channel activation.

\section{Filtering of the receptor potential by electrical membrane properties}

Membrane charging attenuates and slows receptor potentials at high frequencies

$I_{\text {met }}$ depolarizes the hair cell, initiating an RP. In Figure $3 A$, the sinusoidal burst series evoked RPs from an immature striolar type I cell. Below $10-20 \mathrm{~Hz}$, the RP grew (along with $I_{\text {met }}$ ) as a consequence of transducer adaptation. Above $20 \mathrm{~Hz}$, however, the RP fell off as there was insufficient time for $I_{\text {met }}$ to fully charge the membrane cycle by cycle.

In FFTs of the RP from a representative immature striolar type I hair cell (Fig. $3 B$ ), most of the response power was centered at $f_{0}$. In Figure $3 C$, the gain and phase of the $f_{0}$ component of RP referenced to the hair bundle displacement are plotted against 
frequency (average from 6 striolar type I hair cells, $\pm 0.6-1 \mu \mathrm{m}$ stimuli, first postnatal week). The mean best frequency (BF) was $9 \pm 2 \mathrm{~Hz}$ (range, $4-15 \mathrm{~Hz}$ ). The high-pass corner frequency, $f_{\mathrm{HP}}$, was $\sim 1$ $\mathrm{Hz}$, as estimated from the low-frequency roll-off ( $0.8 \pm 0.2 \mathrm{~Hz}, 5$ cells $)$ and as measured in a subset of cells by extending the frequency range to $0.5 \mathrm{~Hz}(1.1 \pm 0.4 \mathrm{~Hz}, 3$ cells; Fig. $3 C$, gray triangles). This value is in reasonable agreement with the slow adaptation time constant obtained for 0.5-1 $\mu \mathrm{m}$ step displacements at $25-29^{\circ} \mathrm{C}: \sim 60$ $\mathrm{ms}$, corresponding to a corner frequency $\left[(2 \pi \tau)^{-1}\right]$ of $3 \mathrm{~Hz}$. Some high-pass filtering (adaptation) may also be mediated by voltage-gated conductances in the haircell membrane (Fig. 3F, discussed in the next section). At $2 \mathrm{~Hz}, I_{\text {met }}$ and RP had similar phase leads: $22 \pm 7^{\circ}$ ( 6 cells, Fig. $2 F)$ and $17 \pm 4^{\circ}$ (6 cells, Fig. 2C), respectively.

Above $10 \mathrm{~Hz}$, the gain and phase of RP decreased relative to that of $I_{\text {met }}$ (data not shown), consistent with low-pass filtering of $I_{\text {met }}$ as a result of membrane charging time. In immature type I cells stimulated with $\pm 0.6-1 \mu \mathrm{m}$ sinusoidal bursts (Fig. $3 C$, filled blue circles), the corner frequency for low-pass filtering, $f_{\mathrm{LP}}$, was $40 \pm 5 \mathrm{~Hz}$ ( 6 cells; range, $24-57 \mathrm{~Hz}$ ). If this filtering is entirely determined by the membrane time constant, then mean $\tau_{\mathrm{m}}$ would be $\left(2 \pi \mathrm{f}_{\mathrm{LP}}\right)^{-1}$ or $4 \mathrm{~ms}$, which is close to the mean $\tau_{\mathrm{m}}(\sim 7 \mathrm{~ms})$ calculated from input resistance and capacitance for a separate population of 16 immature striolar type I hair cells $\left(R_{\mathrm{m}}=899 \pm 202\right.$ $\left.\mathrm{M} \Omega ; C_{\mathrm{m}}=7.7 \pm 0.2 \mathrm{pF}\right)$. For the three cells studied over $0.5-200 \mathrm{~Hz}$ (Fig. 3C, gray triangles), a low quality $(Q$, sharpness) of tuning was measured: $Q_{3 \mathrm{~dB}}=$ $\mathrm{BF} /\left(f_{\mathrm{LP}}-f_{\mathrm{HP}}\right)=0.23 \pm 0.07$.

Thus, for large stimuli, the bandpass filtering of RP is largely attributable to high-pass filtering by adaptation and low-pass filtering by steady-state membrane properties at resting potential.

Electrical resonance of the haircell membrane

Bundle displacements sometimes evoked oscillatory RPs. For example, in the $2 \mathrm{~Hz}$ data from Figure $3 A$ (see asterisk; replotted on an expanded time scale in Fig. 3A.1), the response at the peak of each cycle oscillated. Oscillations were especially long-lasting for small displacement steps (Fig. 3D). Such oscillations were not seen in $I_{\text {met }}$ (data not shown) indicating that they arise at the RP stage. The frequency $\left(f_{\mathrm{e}}\right)$ of the oscillations was a sigmoidal function of step size (Fig. $3 E$ ). The operating range of the $f_{\mathrm{e}}(X)$ relation was similar to the operating range of the RP, as illustrated in Figure $3 E$ by overlaying $f_{\mathrm{e}}(X)$ and peak and steady-state $V_{\mathrm{m}}(X)$ curves for the same cell. In this cell, $f_{\mathrm{e}}$ varied almost 10 -fold over the operating
A1 $2 \mathrm{~Hz}$

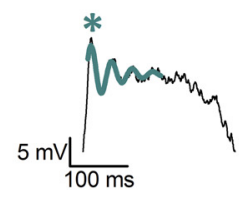

Bundle steps

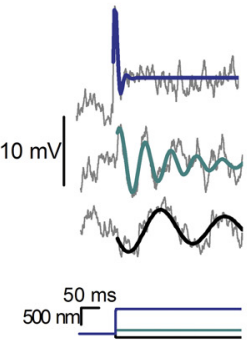

$-50 \mathrm{mV}$

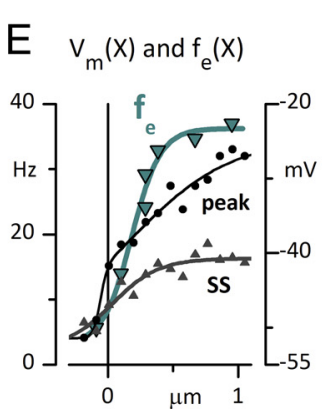

Figure 3. Membrane properties of immature type I hair cells introduce low-pass filtering and electrical tuning. Data shown are from the same $\mathrm{P} 2$ striolar type I hair cell at $27^{\circ} \mathrm{C}$, except in $\boldsymbol{C}$, which are averaged across three or six hair cells. $\boldsymbol{A}, \mathrm{RP}$ evoked by the sinusoidal burst series of bundle displacements shows bandpass tuning, with largest peak-peak amplitudes at 10 and $20 \mathrm{~Hz}$. Asterisk, Part of the $2 \mathrm{~Hz}$ response is expanded in $\boldsymbol{A . 1}$, revealing voltage oscillations. A.1, Cyan curve, Fit of the oscillations (Eq. 7) used to generate $f_{\mathrm{e}}$ and $Q_{\mathrm{e}}$ (Eq. 8) data in $\boldsymbol{G}$ and $\boldsymbol{H}$. $\boldsymbol{B}$, FFT analyses of RP produced by sinusoidal bursts at 2 (left), 20 (middle), and $100 \mathrm{~Hz}$ (right), for $\pm 1 \mu \mathrm{m}$ stimuli. Upper harmonics are at least $15 \mathrm{~dB}$ below the $f_{0}$ peaks. $C$, Bode plots of the mean gain and phase angle of the $f_{0}$ component of RP as functions of frequency for $\pm 0.6-1 \mu \mathrm{m}$ sinusoidal burst stimuli. Blue circles, RP averaged from six hair cells providing $I_{\text {met }}$ data at $27^{\circ} \mathrm{C}$ (Table 1; Fig. 2D). Gray triangles, RP averaged from three hair cells over a wider frequency range $(0.5-200 \mathrm{~Hz})$. Low-pass filtering by the hair-cell membrane decreased the phase lead of RP relative to bundle displacement as frequency increased; it became negative (a phase lag) above $10 \mathrm{~Hz}$. $\mathbf{D}-\boldsymbol{H}, \boldsymbol{A . 1}$, Electrical tuning of the hair-cell membrane contributed to RP tuning in immature striolar type I hair cells. D, RPs evoked by three step displacements of the hair bundle resonated at different frequencies and qualities: $-90 \mathrm{~nm} \operatorname{step}$ (black): $f_{\mathrm{e}}=5.6 \mathrm{~Hz}, Q_{\mathrm{e}}=7.3$; $+100 \mathrm{~nm} \mathrm{step} \mathrm{(cyan):} f_{\mathrm{e}}=14 \mathrm{~Hz}$, $Q_{\mathrm{e}}=6.3 ;+670 \mathrm{~nm}$ step (gray): $f_{\mathrm{e}}=35 \mathrm{~Hz}, Q_{\mathrm{e}}=1 . \boldsymbol{E}_{1} f_{\mathrm{e}}$ and $V_{\mathrm{m}}$ had similar operating ranges of bundle displacement $(X)$, consistent with $f_{\mathrm{e}}$ depending on $V_{\mathrm{m}}$. Both $f_{\mathrm{e}}$ (cyan, left axis) and steady-state (SS) $V_{\mathrm{m}}$ (gray, right axis) were sigmoidal functions of $X$, saturating at $\sim 0.5 \mu \mathrm{m}$. At resting bundle position (steady-state $V_{\mathrm{m}^{\prime}}-47 \mathrm{mV}$ ), $f_{\mathrm{e}}$ was $\sim 8 \mathrm{~Hz}$. Peak $V_{\mathrm{m}}(X)$ relation (black circles)

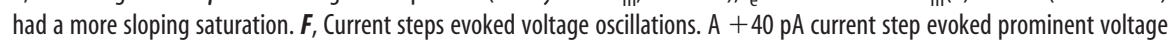
oscillations (violet). Slower voltage oscillations are visible at resting potential (black). A +120 pA step evoked a faster, more damped oscillation (light gray). $\mathbf{G}, \boldsymbol{H}$, Voltage dependence of resonant frequency $\left(f_{e}\right)$ and tuning sharpness $\left(Q_{e}\right)$ overlapped for bundle displacements and current steps. $\mathbf{G}, f_{\mathrm{e}}$ as function of steady-state membrane potential in response to current steps (violet) or bundle steps (dark cyan triangles) or large, low-frequency sinusoidal bundle displacements (bright cyan circles; see $\boldsymbol{A . 1}$ ). The relation was fit with an exponential function (black curve, $R^{2}=0.93$ ). $\boldsymbol{H}, Q_{\mathrm{e}}$ as a function of steady-state $V_{\mathrm{m}}$. Symbols as in $\mathbf{G}$. Tuning was sharpest $\left(Q_{\mathrm{e}}\right.$ largest) near resting potential [i.e., the smallest bundle steps (dark cyan triangles)].

range of the $\mathrm{RP}$, from $\sim 4 \mathrm{~Hz}$ for a negative displacement to $\sim 35$ $\mathrm{Hz}$ for saturating positive displacements.

$\mathrm{RP}$ oscillations reflect voltage-dependent (electrical) tuning of the hair-cell membrane, as shown by current-injection experiments that bypass transduction and directly stimulate voltagesensitive conductances in the hair-cell membrane. Small current steps (Fig. $3 F$ ) evoked voltage oscillations similar to those evoked by displacement steps (Fig. 3D). The sharpness, $Q_{e}$, of the electrical tuning is proportional to the decay time for oscillations (Eq. 8). $f_{\mathrm{e}}$ and $Q_{\mathrm{e}}$ had similar voltage dependence whether the oscillations were evoked by current steps or by displacement steps (Fig. 
A EPSCS

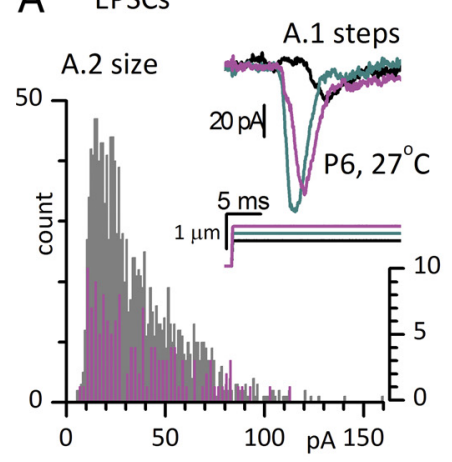

B Synaptic delays

B.1 P3-P4, $28-29^{\circ} \mathrm{C}$

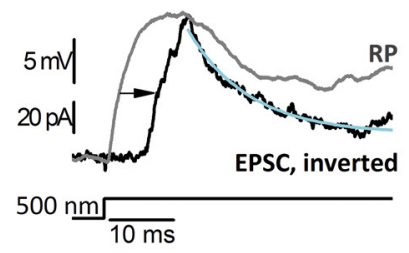

B. 2 P7, $38-39^{\circ} \mathrm{C}$

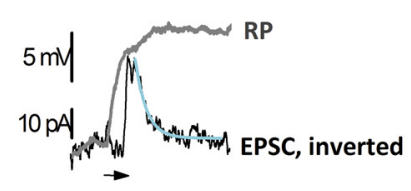

B.3 Averages; $27-28^{\circ} \mathrm{C}$

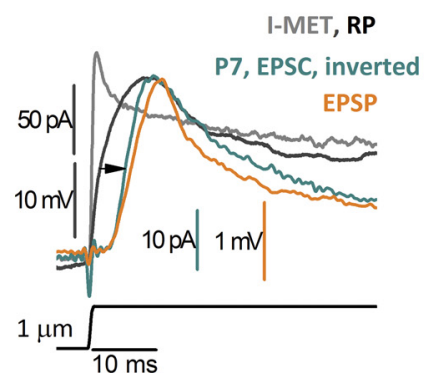

C Levels; $\mathrm{P} 7,27^{\circ} \mathrm{C}$

C.1 steps

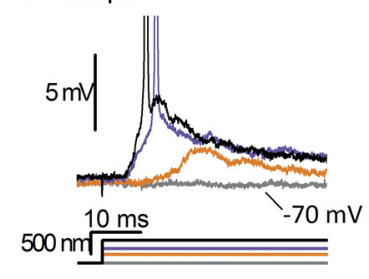

C.2 Averaged EPSPS

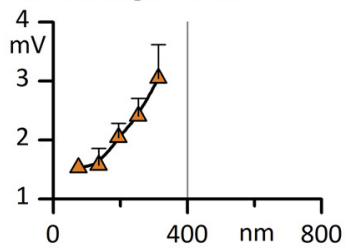

C.3 \#Events/step

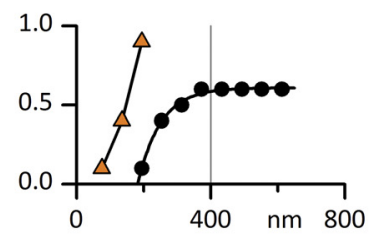

C.4 Latency to peak

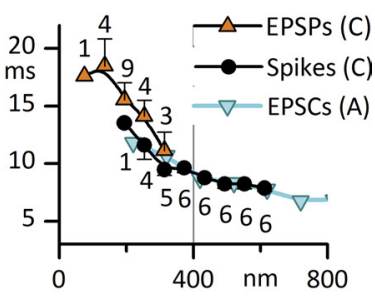

C.5 Jitter

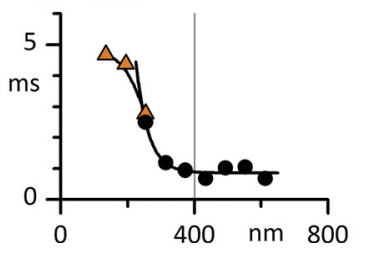

Figure 4. Timing and level dependence of postsynaptic currents, potentials, and spikes recorded from striolar calyces in response to step displacements of type I hair bundles. A, EPSCS. A.1, Responses of a P6 calyx to three positive bundle displacements. Latencies from step onset to onset of first EPSC: $10 \mathrm{~ms}$ for the black step; $6.5 \mathrm{~ms}$ for the cyan and magenta steps. Latencies to first EPSC are plotted against displacement in $\boldsymbol{F}$ (cyan inverted triangles). $\boldsymbol{A} .2$, Distributions of EPSC peak sizes from five striolar complex calyces (gray bars, $25-29^{\circ} \mathrm{C}, \mathrm{P4}-\mathrm{P} 7$ ); the distribution for the calyx of $\boldsymbol{A} \mathbf{.} \boldsymbol{1}$ is superimposed (magenta, expanded count scale on right axis). $\boldsymbol{B}$, Stepevoked RPs from striolar type I hair cells are compared with EPSCs (inverted for comparison) from striolar calyces; records were obtained independently but are matched for stimulus, postnatal age, epithelial zone, and temperature. B.1, Type I: $\mathrm{P3}, 28^{\circ} \mathrm{C}$; calyx: $\mathrm{P} 4$, triple, $29^{\circ} \mathrm{C}$. The delay of the EPSC relative to the RP (arrow) is $6 \mathrm{~ms}$. EPSC decay time constant (cyan curve) is 9.6 $\mathrm{ms}$. The height of the $\operatorname{ESSC}(95 \mathrm{pA})$ suggests summation of five miniature events (vesicles). B.2, P7 type I hair cell at $38^{\circ} \mathrm{C}$ (with low-voltage-activated conductance, $g_{\mathrm{K}, \mathrm{l}}$; see Fig. 10); P7 double calyx at $39^{\circ} \mathrm{C}$. Delay from RP to EPSC (arrow), $2.6 \mathrm{~ms}$. EPSC decay time constant (cyan curve), 1.8 ms. B.3, Averaged EPSCs (inverted, 21 traces) and averaged EPSPs (17 traces) from a P7 double calyx at $27^{\circ} \mathrm{C}$ in response to $+1 \mu \mathrm{m}$ step deflections of a single hair bundle; compare with $I_{\text {met }}$ and RP of a single type I hair cell (same hair cell as in B.1). Mean peak EPSC and EPSP values are $-31 \mathrm{pA}$ and $2.2 \mathrm{mV}$, corresponding to $\sim 1.5-2$ vesicles (based on size distribution data in $A$ ). Synaptic delay from averaged RP to averaged EPSC (arrow), $4.6 \mathrm{~ms}$. Monoexponential fits to the decays of the averaged EPSC and EPSP had time constants of 15.1 and $7.7 \mathrm{~ms}$, respectively (fits not shown). C, Level dependence of EPSPs and spikes evoked in a double calyx by step deflections of one of its input hair bundles $\left(P 7,27^{\circ} \mathrm{C}\right)$. C.1, As level (bundle displacement)

$3 G, H)$, consistent with a common mechanism. As found in other hair cells (Crawford and Fettiplace, 1981), $Q_{\mathrm{e}}$ had a somewhat bell-shaped dependence on membrane potential, peaking sharply near resting potential.

The mean best $f_{\mathrm{e}}$ (frequency corresponding to the highest $Q_{\mathrm{e}}$ ) was $29 \pm 4 \mathrm{~Hz}$ in seven cells, higher than best frequencies obtained with sinusoidal bursts ( $\sim 9 \mathrm{~Hz}$, Fig. $3 C)$. $Q_{\mathrm{e}}$ peaked at 7.5 for a small step displacement (Fig. $3 H$ ), a value much higher than the $Q_{3 \mathrm{~dB}}$ value $(\sim 0.2$, Fig. $3 C$ ) of Bode plots for sinusoidal bundle displacements. The difference reflects the strong voltage dependence of $Q_{e}$ (Fig. $3 H$ ): the large sinusoidal motion used for the Bode plots in Figure $3 C$ depolarized the hair cell to values positive to $-40 \mathrm{mV}$, where $Q_{\mathrm{e}}$ was low.

Thus, in immature striolar type I hair cells, electrical tuning boosts receptor potentials to stimulus frequencies from several hertz to tens of hertz, with the greatest effect for small transduction currents. Such enhancement may be important in driving transmitter release and downstream activity in the developing vestibular system. As described later in Results, the electrical resonance of the early postnatal period is soon eliminated in type I cells by maturational changes that broaden membrane filtering.

\section{Postsynaptic responses from striolar calyces}

Calyceal responses to steps reveal synaptic delay and narrow operating range

Deflecting the hair bundle of a type I hair cell evoked activity in its postsynaptic calyx, which we recorded in voltage clamp as currents (EPSCs) and in current clamp as subthreshold potentials (EPSPs). In Figures 4 and 6, we analyze EPSCs, EPSPs, and spikes from calyces in which the transmission appeared to be predominantly quantal. In Figure 5, we illustrate examples in which a nonquantal response dominates. Figure 4 features quantal events and spikes evoked by step displacements. In a P6 calyx, increasing step size increased the size and decreased the latency of EPSCs (Fig. 4A.1), reaching an asymptote at $7.5 \mathrm{~ms}$ (Fig. 4C.4, cyan curve). The distributions of EPSC peak amplitudes from this calyx are plotted in Figure 4A.2 (magenta), superimposed on the pooled distribution of 1424 EPSCs from five calyces at $25-29^{\circ} \mathrm{C}$ (gray). The EPSCs were collected during trials with hair bundle deflections. For the pooled distribution, mean amplitude was $34.5 \pm 0.6 \mathrm{pA}$, median amplitude was $28 \mathrm{pA}$, mode was $15 \mathrm{pA}$, and the largest event was $159 \mathrm{pA}$. A Gaussian fit to the values between 0 and $33 \mathrm{pA}$ (data not shown) was centered at $19.9 \pm 0.6$ $\mathrm{pA}$ (SEM) with an SD of $8 \mathrm{pA}$. Adjusting for the reduced driving force in our data $(-65 \mathrm{mV})$ compared with published data from

$\leftarrow$

increased (bottom traces), EPSP latency decreased and EPSP size increased until spike threshold $(\sim-63 \mathrm{mV}$ in this calyx) was crossed (purple trace). A further increase in bundle displacement reduced spike latency (black trace). C.2-C.5, In mixed EPSP and spike responses (as in C.1), EPSPs (orange triangles) and spikes (black circles) were analyzed separately. EPSP traces that did not give rise to spikes were averaged together ( $n$ 's for EPSPs for $C .4$ and $C .5$ are given in $C .4$ next to the data points). EPSPs at levels above spike threshold are not shown; instead, spikes are counted. C.2, Average EPSP peak size increased from $1.5 \mathrm{mV}(\sim 1$ quantum) at displacements $<200 \mathrm{~nm}$ to $3 \mathrm{mV}$ ( 2 quanta) at $300 \mathrm{~nm}$. All EPSPs occurred near the beginning of the step, but because of jitter in their timing $(\boldsymbol{C . 5})$, aligning the averaged traces by the onset of the displacement step reduced the peak relative to an average made by aligning quantal events (data not shown). C.3, Number of events per step. This calyx lacked spontaneous activity; EPSPs were first detected at $+75 \mathrm{~nm}$ and increased in number per step until they started triggering spikes at $+200 \mathrm{~nm}$. C.4, C.5, Latency (C.4, step onset to response peak) and jitter (C.5) declined for both EPSPs and spikes as bundle displacement increased up to $\sim 300 \mathrm{~nm}$. At higher levels, spike latency (measured at spike peak) and jitter plateaued at 7.9 and $0.7 \mathrm{~ms}$, respectively. C.4, Cyan triangles, First EPSC latencies from the calyx of $\boldsymbol{A} .1$ show a long minimum latency similar to that for spikes in the calyx featured in $\boldsymbol{C}$. 
cochlear and vestibular terminals $(-80$ to $-90 \mathrm{mV}$ ) yields a modal value of $20 \mathrm{pA}$, which can be compared with $21 \mathrm{pA}$ in mouse utricular calyces (Dulon et al., 2009), 18 pA for P5-P19 afferents on outer hair cells (Weisz et al., 2009), and 30 pA for P8-P11 afferents on inner hair cells (Grant et al., 2010). If our modal value ( $15 \mathrm{pA}$ in our conditions) represents the quantal size at these immature rat calyces, then the maximum value of $\sim 160$ pA corresponds to release of 10-11 vesicles, and the median and mean values both correspond to approximately two vesicles.

For EPSCs from the exemplar calyx in Figure 4A.1, the mean time to peak was $2.9 \pm 0.2 \mathrm{~ms}(n=20$ events $)$ and the mean decay time constant for 16 events with monoexponential decays was $3.1 \pm 0.2 \mathrm{~ms}$, in between values from similarly aged mouse utricular calyces (P4-P9; room temperature; time constant, 5-6 ms; Dulon et al., 2009) and the average value for a mature gerbil calyx (1 ms, Rennie and Streeter, 2006). Figure $4 B$ demonstrates that most of the long EPSC latency to the step stimuli in Figure 4A.1 arises at the synapse. We estimated synaptic delay by comparing the presynaptic signal from type I hair cells (the RP) and the postsynaptic signal (EPSC, inverted for comparison) from striolar calyces, matched for stimulus, age range, zone, and temperature. In the P4 calyx of Figure 4 B.1, the EPSC lagged the exemplar RP by $6 \mathrm{~ms}$ (arrow; delay measured at midpoint of rise). This EPSC was quite slow: its long time to peak $(6.5 \mathrm{~ms})$ and decay time constant $(15.1 \mathrm{~ms})$ are likely to reflect temporal dispersion of overlapping quanta (synaptic vesicles). Pairing the same RP with the faster EPSCs for the same step size from Figure $4 A .1$ yields a similar synaptic delay ( $5.8 \mathrm{~ms}$, data not shown). Immaturity and low temperature are likely to contribute to the long delay, as suggested by a delay of just $2.4 \mathrm{~ms}$ in a more mature pairing at body temperature (Fig. 4 B.2, arrow). The EPSC time to peak $(740 \mu \mathrm{s})$ and decay time constant $(1.8 \mathrm{~ms})$ were also relatively fast. More data are needed to isolate and quantify the effects of maturation and temperature. Figure $4 B .3$ compares averaged transduction current and receptor potential from a striolar type I hair cell with averaged EPSC and EPSP responses from a third calyx, older but at $27^{\circ} \mathrm{C}$, to saturatingly large $(1 \mu \mathrm{m})$ steps. Relative to the averaged RP, the averaged EPSC was delayed by $4.0 \mathrm{~ms}$ (black arrow). The corresponding averaged EPSP (orange trace) had little additional delay.

In summary, the synaptic delays for quantal transmission (4-6 $\mathrm{ms}$ at room temperature) in these immature calyces are not consistent with in vivo data from more mature vestibular afferents. A similar delay characterizes the entire angular vestibuloocular reflex (VOR), which involves four synapses, measured in vivo from mature primates (Huterer and Cullen, 2002). Moreover, synaptic delay in mature cat saccular afferents was estimated at $<0.5 \mathrm{~ms}$ (McCue and Guinan, 1994; see Discussion). It is not surprising, however, to find that synaptic transmission is immature in the rat saccular macula in the first postnatal week. At P9-P11 in the rat cochlea, afferent terminal EPSCs evoked by step depolarizations of inner hair cells also take several milliseconds to peak (Goutman and Glowatzki, 2007). Other hair-cell and synapse properties are immature at this time in rodent vestibular epithelia. During the first two postnatal weeks, calyces of the mouse utricle mature morphologically (Rüsch et al., 1998) and ion channels are added to the hair cells (see Fig. 10) and parent cell bodies in the vestibular ganglion (Kalluri et al., 2010).

In Figure $4 C$, we examine the level dependence of EPSPs and spikes from a P7 double calyx with no spontaneous activity. Responses for several steps of different size are superimposed in Figure 4C.1. At the low end of the operating range, 50 to 200-300 $\mathrm{nm}$, increasing the bundle deflection increased EPSP peak ampli- tude (Fig. 4C.2) and EPSP number (Fig. 4C.3), and decreased EPSP latency (Fig. 4C.4) and EPSP jitter (Fig. 4C.5). The smallest EPSPs (mean, $1.5 \mathrm{mV}$; Fig. 4C.2) may have been "minis" generated by single synaptic vesicles and corresponding to EPSCs of $\sim 15$ pA; maximum subthreshold EPSPs were $3 \mathrm{mV}$ (Fig. 4C.2). In two other calyces $\left(\mathrm{P} 5,25-29^{\circ} \mathrm{C}\right)$, minimum EPSPs were 2.0 and $1.6 \mathrm{mV}$ and maximum subthreshold EPSPs were 4.4 and 8.4 $\mathrm{mV}$ (data not shown). Thus, at this age and temperature, $\sim 2-3$ vesicles were needed to produce a spike.

For bundle displacements between 200 and $400 \mathrm{~nm}$, responses transitioned from EPSPs to spikes (Fig. 4C.1,C.3). The response of this calyx was strongly adapting (phasic), such that just one onset spike was produced at any level. The latency of spike peaks (Fig. 4C.4), however, had a broader level dependence, asymptoting at $\sim 8 \mathrm{~ms}$ for the largest stimuli. This long minimal latency exceeds the synaptic delay $(4-6 \mathrm{~ms}$, Fig. $3 B$ ), indicating that other processes, such as charging of the presynaptic and postsynaptic membranes, also take significant time in this immature preparation. Between 200 and $400 \mathrm{~nm}$, spike jitter (Fig. 4C.5) fell steeply from $\sim 5 \mathrm{~ms}$ to $\sim 1 \mathrm{~ms}$. In a model of hair-cell exocytosis (Wittig and Parsons, 2008), jitter depends inversely on the number of readily releasable vesicles, with a jitter of $\sim 1 \mathrm{~ms}$ (similar to the value for $>300 \mathrm{~nm}$ in Fig. 4C.5) produced by a simulation for two releasable vesicles. Thus, our jitter values together with the evidence for few releasable vesicles (above) are consistent with predictions from the model.

For bundle displacements of $>400 \mathrm{~nm}$, spike responses in the calyx of Figure $4 C$ were largely independent of level in number, latency, and jitter. Thus, the spike OR $(\sim 150 \mathrm{~nm})$ was just a fifth of the typical OR for $I_{\text {met }}$ (Table 1), indicating that posttransduction mechanisms compress the OR, consistent with cochlear data (Weiss, 1984; Eatock et al., 1991). These mechanisms may include voltage-dependent properties of the hair-cell and calyceal membranes, synaptic adaptation or fatigue, and refractoriness in the spike generator, any or all of which may be especially pronounced in developing synapses.

Postsynaptic responses to sinusoids reveal nonquantal components and bandpass tuning

To study frequency tuning of EPSCs and EPSPs in calyces, we delivered a series of sinusoidal bursts, usually from 2 to $100 \mathrm{~Hz}$, at a smaller level $( \pm 300 \mathrm{~nm})$ than our standard for hair-cell responses $( \pm 600-1000 \mathrm{~nm})$. The larger stimuli were needed to map the full $I(X)$ relations in hair cells, whereas the smaller stimuli allowed us to isolate more subthreshold EPSPs in calyces. Calyceal spiking data were collected at both levels.

Quantal and nonquantal components of calyceal responses Mechanical stimulation sometimes evoked calyceal currents (in voltage clamp) or subthreshold potentials (in current clamp) that appeared to be nonquantal, with different shapes and latencies from quantal (vesicular) events. Nonquantal responses of two calyces are illustrated in Figure 5. Qualitatively similar responses were previously reported in intracellular recordings from chick and turtle calyx-bearing canal afferents stimulated by displacement of canal fluids (Yamashita and Ohmori, 1990; Holt et al., 2007). In the turtle, the nonquantal component occurred together with conventional quantal transmission in individual afferents. Since the turtle afferents may have innervated both type I and type II hair cells, it was not clear whether both forms of transmission occur in the same calyx ending at once. Our results show that nonquantal responses can occur in mammals, at least in the first postnatal week, and that they originate in calyx endings and can occur alone or in combination with quantal responses. 
A Calyx NQ response to bundle steps $P 527^{\circ} \mathrm{C}$

A.1 Sustained NQ responses
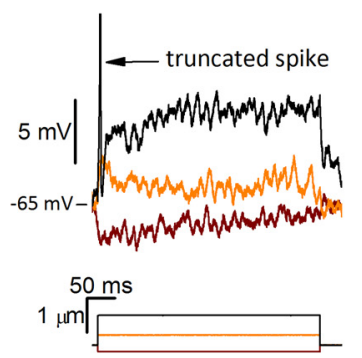

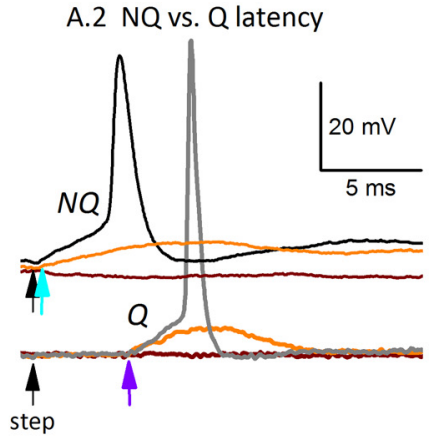

B NQ responses to sines

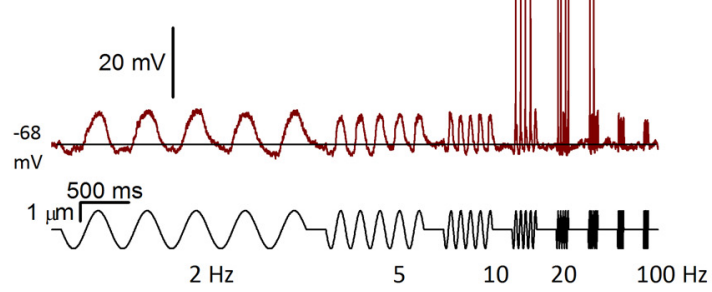

C NQ and Q responses from double calyx, $\mathrm{P} 425^{\circ} \mathrm{C}$ NQ bundle 1
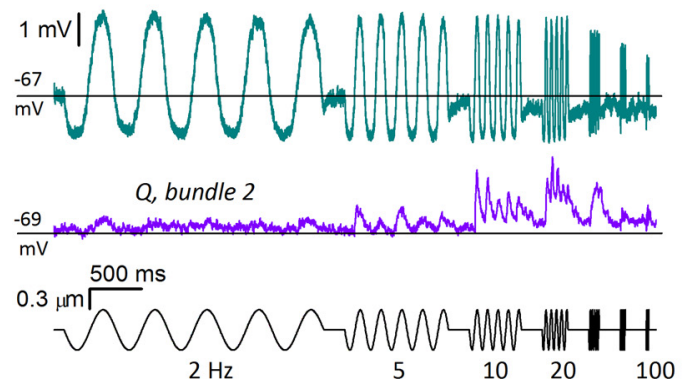

Gain and phase: NQ vs. Q
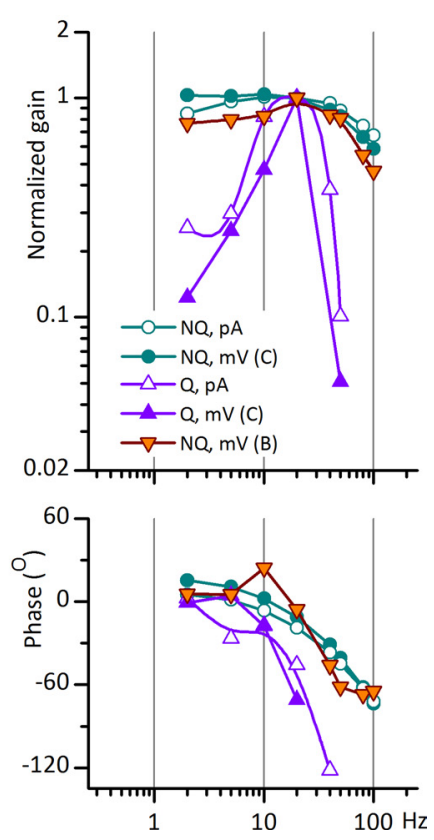

Figure 5. Timing and tuning differ for quantal (Q) and nonquantal (NQ) transmission at calyceal synapses. Data shown are from three exemplar calyces, all in the first postnatal week and recorded at $25-29^{\circ} \mathrm{C}$. $A$, Voltage responses from a double calyx $\left(\mathrm{P5}, 27^{\circ} \mathrm{C}\right)$ during step stimulation of one of the two hair bundles. $A .1$, Steps evoked long-lasting (tonic) voltage responses quite different from EPSPS, which are discrete and have a positively skewed shape (examples in Figs. 4B,C.1, 5C). Large stimuli triggered a single spike (black trace). $A .2$, Nonquantal responses in $A .1$ are compared, on an expanded time scale and compressed voltage scale, to quantal responses to similar step stimuli recorded in an adjacent double calyx of the same preparation. The two sets of traces are aligned horizontally, with black arrows showing step onset; vertical scaling is the same for both sets of data but vertical alignmentis arbitrary. The onset of the nonquantal response (top, cyan arrow) precedes the onset of quantal responses (bottom, purple arrow) by $>4 \mathrm{~ms}$. Contrast the discrete EPSP in the quantal response to the sustained depolarization in the subthreshold nonquantal response (orange traces). Notealso that the negativestep (brown) evoked a hyperpolarizing nonquantal response (expanded in $\boldsymbol{A . 1}$ ) but no quantal response. $\boldsymbol{B}$, Voltage response from the calyx of $\boldsymbol{A} . \boldsymbol{1}$ (single trace) to sinusoidal burst stimuli. From 2-10 and $80-100 \mathrm{~Hz}$, nonquantal potentials were sizeable but subthreshold; at 20, 40, and $50 \mathrm{~Hz}$, they evoked spikes. The nonquantal response to the negative-going phase of the sinusoid dipped below resting potential (blackline). C, Different modes of transmission from two hair cells within one striolar double calyx $\left(\mathrm{P4}, 25^{\circ} \mathrm{C}, \pm 300 \mathrm{~nm}\right.$ sinusoidal bursts). The two hair bundles were stimulated one at a time in sequence. Stimulating bundle 1 evoked nonquantal transmission (cyan, average of 4 traces); stimulating bundle 2 evoked conventional EPSPs from the same calyx (purple, average of 10 traces). Same voltage scale for both traces. Results were consistent as the probe placement was alternated between the two hair bundles several times. The quantal response was moretuned. Black lines show resting potential; thenonquantal response had a strong hyperpolarizing component but the quantal response did not, as expected for quantal transmission on a baseline of zero spontaneous activity. $D$, Bode plots of $f_{0}$ components of quantal and nonquantal responses. Relative to quantal-response tuning (purple traces), nonquantal tuning for both calyces (cyan and orange symbols) was much broader and, for stimulus frequencies of $>5 \mathrm{~Hz}$, had less phase lag (phase angles were less negative). Included are Bode plots for postsynaptic currents from the calyx of $C$ : EPSCs driven by bundle 2 displacements (open purple triangles) and nonquantal currents driven by bundle 1 displacements (open cyan circles). Gain plots were normalized to peak values for ease of comparison.

In Figure 5, we highlight nonquantal responses well isolated from quantal responses. Figure $5 A$ shows voltage responses from a calyx to step deflections of the hair bundle of one of its enclosed type I hair cells. Steps evoked sustained voltage changes (Fig.
5A.1) with superimposed voltage noise that did not resemble EPSPs in shape; the largest step evoked a spike at step onset. The sustained voltage responses do not appear to reflect summation of many EPSPs. Further, the latencies of nonquantal responses were much shorter than the latencies of quantal responses, as illustrated on an expanded time scale in Figure 5A.2. The nonquantal response started (cyan arrow) within $0.5 \mathrm{~ms}$ after step onset (black arrow). Immediately below are shown, for comparison, quantal responses to similar stimuli from a different calyx; the quantal responses started $5 \mathrm{~ms}$ after the step (purple arrow), consistent with quantal latencies in Figure 4A.1. The 10 -fold reduction in latency in the nonquantal case argues strongly for a fundamentally more direct mechanism, such as a form of electrical transmission (see Discussion). In Figure 5A.2, the spike evoked by the largest step peaked at $4.6 \mathrm{~ms}$ after the step for the nonquantal case, in contrast to $8.2 \mathrm{~ms}$ for the quantal case. The quantal spike latency was similar to the lowest spike latencies in a different calyx with quantal transmission $(8.3 \mathrm{~ms}$; Fig. 4C.4). Figure $5 B$ shows the response of the nonquantal calyx of Figure $5 A$ to sinusoidal bursts from 2 to $100 \mathrm{~Hz}$. Large quasi-sinusoidal postsynaptic potentials triggered spikes at 20,40 , and $50 \mathrm{~Hz}$ with a spike threshold of $-56 \mathrm{mV}$. Consistent with the negative step displacement data in Figure $5 A$, negative-going phases of the sinusoidal stimuli elicited hyperpolarizations (below resting potential, black line). Hyperpolarization is not expected for a quantal response except through inhibition of a strong background level of quantal summation; in this calyx, there were no spontaneous quantal events.

Quantal and nonquantal transmission can be recorded from one calyx. In the double calyx of Figure $5 C$, the nature of transmission depended on which of its two type I hair cells was stimulated: deflection of one bundle evoked nonquantal responses (cyan) and deflection of the other bundle evoked quantal responses (purple). This difference in transmission mode was sustained for more than $1 \mathrm{~h}$, during which the stimulus probe was repeatedly switched from one bundle to the other. Again, the large hyperpolarizing component of the nonquantal response (negative to the black line) is difficult to reconcile with a quantal mechanism. For comparison, the entire quantal response is above the line representing resting potential.

In other calyces (data not shown), responses to motion of a single bundle had both nonquantal and quantal components. 
Both components were always eliminated by moving the stimulus probe slightly off the hair bundle, showing that neither component was an electrical artifact. Possible mechanisms for nonquantal transmission are considered in Discussion.

The frequency dependence of nonquantal and quantal responses from these two calyces are plotted together in Figure $5 D$. The nonquantal, subthreshold responses of the calyx from $A$ and $B$, plotted as orange inverted triangles in Figure $5 D$, had broad filtering with diminishing gain and phase above $20 \mathrm{~Hz}$. For the calyx with both nonquantal and quantal transmission, the nonquantal response [recorded in voltage clamp (cyan open circles) and current clamp (cyan filled circles)] was much more broadly tuned than the quantal response (open and closed purple triangles). The phases of nonquantal responses led the phases of quantal responses, especially above $5 \mathrm{~Hz}$, consistent with the shorter latency of nonquantal responses to steps (Fig. 5A.2).

To recapitulate, some calyceal responses to hair bundle deflections appeared to be quantal (Fig. 4), as expected from other hair-cell synapses. Others appeared to be nonquantal (Fig. 5) because they lacked individual events with the skewed shape of quantal responses, and had much shorter latencies (Fig. 5A.2) and prominent hyperpolarizing components (Fig. $5 A-C$ ). In some cases, it appeared possible that the response to a single bundle deflection included both nonquantal and quantal components (data not shown), but confirmation awaits pharmacological experiments to block one or the other component (Holt et al., 2007). Where both components are present, the FFTs that we used to generate Bode plots of gain and phase versus frequency would reflect contributions from both components. FFT analysis is not eventbased, unlike many kinds of synaptic analysis, and will therefore agnostically report any stimulus-driven signal. Note also that, in contrast to spontaneous quantal events, there is no signature of nonquantal transmission in the absence of a mechanical or electrical stimulus to the hair cell.

Frequency dependence of EPSCs and EPSPs

Figure 6 further explores the frequency dependence of postsynaptic responses, focusing on responses with less prominent (if any) nonquantal components than in the calyces of Figure 5. In Figure $6 A$, EPSCs and EPSPs were recorded from a striolar triple calyx in response to $\pm 300 \mathrm{~nm}$ sinusoidal bursts applied to one of the three hair bundles; responses to stimulation of a second bundle within this triple calyx were qualitatively similar to those shown. The averaged EPSCs were largest for stimuli between 10 and $40 \mathrm{~Hz}$. During the burst series, there were slow shifts of baseline inward current (in voltage-clamp recording of EPSCs) and depolarization (in current-clamp recording of EPSPs) away

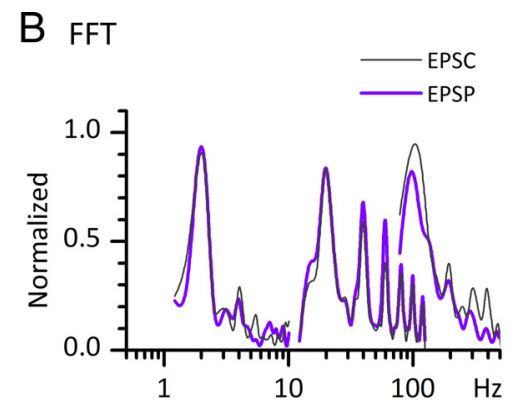

D EPSCs re: RP

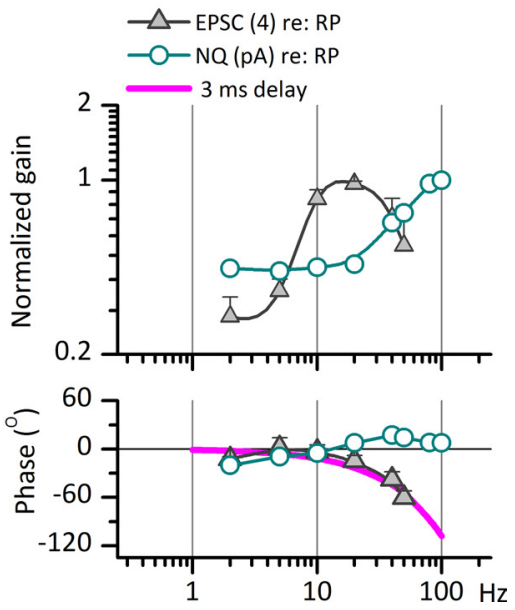

Figure 6. The frequency dependence of postsynaptic currents and potentials recorded from striolar calyces in response to sinusoidal displacements of type I hair bundles. All signals were evoked by $\pm 300 \mathrm{~nm}$ sinusoidal burst series from $2 \mathrm{to} 100 \mathrm{~Hz}$. $\boldsymbol{A}$ (top, 5 traces averaged) and EPSPs (bottom, 7 traces averaged) from a P4 triple calyx at $29^{\circ} \mathrm{C}$. Black lines aligned with at synaptic stages. $\boldsymbol{B}$, FFTs of averaged EPSC and EPSP responses in $\boldsymbol{A}$ at 2,20 , and $100 \mathrm{~Hz}$ and $\pm 300 \mathrm{~nm}$. At 2 and $100 \mathrm{~Hz}$, higher harmonics were at least $15 \mathrm{~dB}$ below the $f_{0}$ component. At $20 \mathrm{~Hz}$ (best frequency for this calyx), higher harmonics were significant. $\boldsymbol{C}$, Bode plots of gain and phase versus burst frequency for $\pm 300 \mathrm{~nm}$ stimuli (see $\boldsymbol{A}, \boldsymbol{B}$ ). Left axis, EPSCs ( $f_{0}$ component, $n=4$ calyces). For EPSPs (right axis, from the same calyces), we plot the $f_{0}$ component of FFTs (filled circles), and peak values of EPSPS ata as in C) and nonquantal (NQ) current (1 calyx, from Fig. 5C), both referenced to RP data from a type I hair cell. All measurements for $f_{0}$ component from FFT analysis of responses to the $\pm 300 \mathrm{~nm}$ sinusoidal burst series. The fall-off at high frequencies of the phase lead of EPSCs referenced to RPs (gray triangles) was well fit with a simple delay term of $3 \mathrm{~ms}$ (magenta curve), consistent with an average synaptic delay of $3 \mathrm{~ms}$.

from the resting values indicated by black lines in Figure $6 A$. Such shifts were not seen in receptor potential recordings (Fig. $3 A$ ), suggesting accumulation of some factor, such as presynaptic $\mathrm{Ca}^{2+}$ or neurotransmitter in the synaptic cleft.

FFTs of the EPSC and EPSP data in Figure $6 \mathrm{~A}$ are plotted in Figure $6 B$ for 2, 20, and $100 \mathrm{~Hz}$ sinusoidal bursts. As expected for quantal responses, these EPSCs and EPSPs were less sinusoidal (more positively skewed) than $I_{\text {met }}$ (Fig. 2), RP (Fig. 3), and nonquantal currents or voltages (Fig. 5). This distortion manifested as additional peaks in the FFTs for EPSCs and EPSPs at frequencies above the fundamental frequency, $f_{0}$. Distortion was most prominent for the large, synchronized signals near the best frequency for the calyx $(20 \mathrm{~Hz}$; Fig. $6 \mathrm{~A})$, with clear FFT peaks at multiple harmonics of $f_{0}$.

The Bode plots of the gain and phase of $f_{0}$ components of EPSCs and EPSPs referenced to bundle displacement (Fig. 6C) were averaged from four striolar calyces. The gains peak at $20 \mathrm{~Hz}$ and at $<10 \mathrm{~Hz}$ there is a phase lead of $10-15^{\circ}$. Bode plots for EPSCs (filled circles) and EPSPs (open circles) in the same calyces were similar, indicating that the calyceal membrane did not add 
A Voltage steps

A.1 Striolar calyx

P7 $26^{\circ} \mathrm{C}$

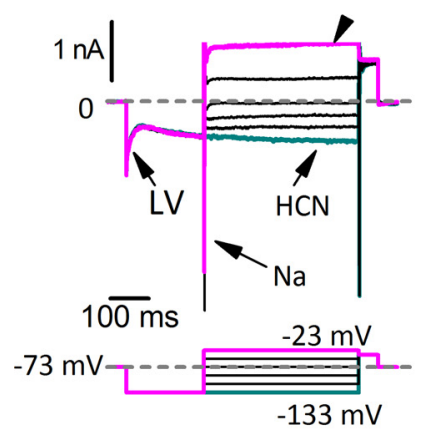

A.2 Striolar calyces I(V)

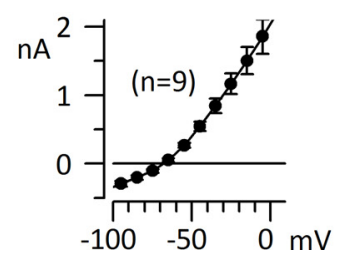

B

Current steps

B.1 Striolar calyx

P4 $27^{\circ} \mathrm{C}$
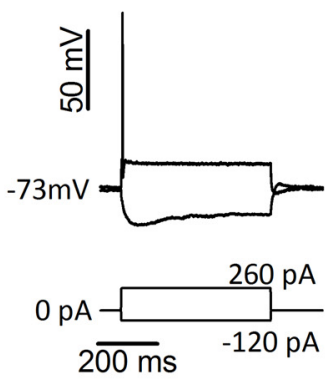

B.2 Extrastriolar calyx

P8 $27^{\circ} \mathrm{C}$

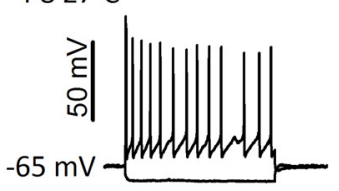

C Spontaneous activity

C.1 Striolar calyx

P8 $37^{\circ} \mathrm{C}$

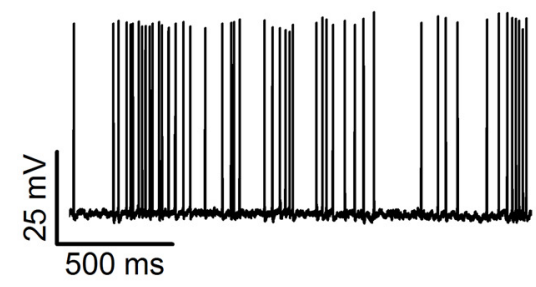

C. 2 Extrastriolar calyx

P8 $27^{\circ} \mathrm{C}$

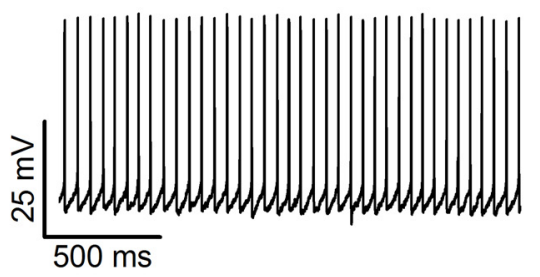

ISI

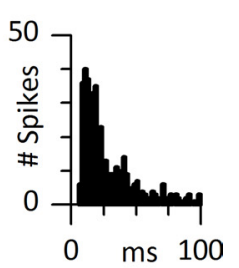

Figure 7. Striolar calyces had low-voltage-activated K channels, transient firing patterns in response to current steps, and irregular interspike intervals. A.1, Voltage-dependent currents recorded in voltage-clamp mode from a striolar double calyx. A hyperpolarizing prepulse from the holding and resting potential of - $73 \mathrm{mV}$ (dashed lines) turned off a low-voltage-activated current (LV, fast decline in inward current) and activated HCN current (cyan, slow increase in inward current). Depolarizing steps activated transient Na ${ }^{+}$current and a sustained outward current (arrowhead) carried by $\mathrm{K}_{\mathrm{LV}}$ channels and likely others. $R_{\mathrm{m}}, 48 \mathrm{M} \Omega ; C_{\mathrm{m}}, 7.7 \mathrm{pF}$. A.2, Averaged $/(V$ relation, taken $100 \mathrm{~ms}$ after step onset, for nine striolar complex calyces: six double calyces (each enveloping 2 type I cells) and three triple calyces (each enveloping 3 type I cells). The slope resistance around the average zero-current potential $(-69 \mathrm{mV})$ was $56 \pm 2 \mathrm{M} \Omega$, a low value consistent with the expression of $L V$ and HCN channels, which are activated at resting potential. $\boldsymbol{B}$, Current steps evoked different firing patterns depending on epithelial location. $\boldsymbol{B}$. 1 , Transient (onset) firing in a striolar complex calyx. B.2, Sustained firing in an extrastriolar simple calyx (contacting 1 type I hair cell). C, Spontaneous spike timing was consistent with in vivo data specifying how timing varies with epithelial zone. C.1, A P8 striolar "quadruple" calyx (with 4 type I hair cells) was highly irregular. C.2, P8 extrastriolar simple calyx (same as in B.2) was highly regular. To simplify comparison of spike timing, we chose data with similar mean rates: 19.5 (striolar) and 19.0 (extrastriolar) spikes/s. Right, ISI distributions: coefficient of variation: 1.28 for the irregular striolar calyx, 0.05 for the regular extrastriolar calyx.

filtering in this frequency range at this stimulus level. This result is consistent with expression by striolar calyces of low-voltageactivated channels (next section), which decrease membrane filtering in the frequency range of $<100 \mathrm{~Hz}$.

By measuring contributions only at $f_{0}$ and neglecting the higher harmonics resulting from the skewed shapes of quantal EPSCs and EPSPs (Fig. 6B), our standard Bode analysis may underestimate gains and phase leads of EPSCs and EPSPs. Therefore, we also generated Bode plots of the measured heights and timing of EPSP peaks (Fig. 6C, open circles). The two methods yielded similar gain curves, but peak phases led $f_{0}$ phases by about $20^{\circ}$ (an expected effect for sinusoidal fits at $f_{0}$ of positively skewed events). In computing the phase of spikes relative to EPSPs (next section), we use EPSP phases calculated in both ways.

In Figure $6 D$, the effect of synaptic mechanisms on response dynamics is revealed by referencing EPSC magnitude and phase to RP data from a type I hair cell matched for age, zone, stimulus level, and temperature. The frequency-dependent phase lag of EPSC relative to RP was well fit by a simple 3 ms delay (Fig. $6 D$, magenta curve), similar to the $4 \mathrm{~ms}$ value for the averaged step data in Figure 4 B.3. For comparison, the gain and phase of nonquantal current data from the calyx of Figure $5 C$ were also referenced to RP (cyan open circles; both gain curves are normalized to their peak values). In contrast to the quantal synaptic transfer function, the gain of the nonquantal synaptic transfer function increased with frequency and its phase never fell below zero, consistent with the very short synaptic delay at nonquantal synapses (Fig. 5A.2). The nonquantal and quantal synaptic transfer functions in Figure $6 D$ were calculated with reference to the same type I RP data (chosen from the group characterized in Fig. $3 C$ ), but it is possible that the receptor potential input to nonquantal and quantal synapses differs systematically.

\section{Calyceal spiking}

$K_{L V}$ currents, step-evoked firing patterns, and spike regularity In isolated somata of primary vestibular afferents, the expression of low-voltage activated $\mathrm{K}^{+}\left(\mathrm{K}_{\mathrm{LV}}\right)$ currents is associated with a transient (onset) spike response to depolarizing current steps (Iwasaki et al., 2008; Kalluri et al., 2010). Blocking the $\mathrm{K}_{\mathrm{LV}}$ channels converts the firing pattern from the transient response to sustained, highly regular firing, suggesting that $\mathrm{K}_{\mathrm{LV}}$ channels are essential to the irregular afferent firing characteristic of striolar and canal central-zone afferents in vivo. This hypothesis is strengthened by recordings illustrated in Figure 7, taken from striolar calyces within several micrometers of the spike initiation zone (Lysakowski et al., 2011), which reveal $\mathrm{K}_{\mathrm{LV}}$ currents (Fig. $7 A$ ), transient evoked firing patterns (Fig. $7 B$ ), and irregular spontaneous activity (Fig. 7C).

In voltage-clamp recordings from nine striolar complex calyces ( 6 doubles, 3 triples), stepping from -60 or $-70 \mathrm{mV}$ to -125 $\mathrm{mV}$ (Fig. 7A.1) deactivated a low-voltage-activated (LV) current and activated HCN currents (Meredith et al., 2012). The steadystate $I(V)$ relation, averaged across the nine calyces in Figure $7 A .2$, had a mean zero-current potential near $-70 \mathrm{mV}$ and a mean slope resistance at $\sim-70 \mathrm{mV}$ of $50-60 \mathrm{M} \Omega$, a relatively low value consistent with the activated state of many $\mathrm{HCN}$ and 
Table 2. Variation in spike rate and regularity with temperature and epithelial zone

\begin{tabular}{llllcc}
\hline Zone & ${ }^{\circ} \mathrm{C}$ & $n$ & Age, days & Spikes/s & CV \\
\hline Striola & $25-29$ & 5 & $7.4 \pm 0.2$ & $6.3 \pm 2.1$ & $1.14 \pm 0.25$ \\
Extrastriola & $25-29$ & 9 & $6.3 \pm 0.2$ & $15.3 \pm 2.0, p<0.014^{a}$ & $0.24 \pm 0.06$ \\
Striola & $35-39$ & 4 & $6.5 \pm 0.9$ & $19.8 \pm 3.7, p<0.013^{b}$ & $1.59 \pm 0.53$ \\
\hline
\end{tabular}

Relative to striolar afferent spike rates at $25-29^{\circ} \mathrm{C}$, mean spike rates were significantly higher for extrastriolar afferents at $25-29^{\circ} \mathrm{C}^{a}$ and for striolar afferents at $35-39^{\circ} \mathrm{C}^{b}$. $\mathrm{CV}^{\mathrm{C}}$ and Fano factor $(\mathrm{FF})^{d}$ were both significantly lower for extrastriolar afferents than for striolar afferents (comparison shown for $25-29^{\circ} \mathrm{C}$ ).

$\mathrm{K}_{\mathrm{LV}}$ channels at resting potential. Depolarizing steps activated rapidly inactivating $\mathrm{Na}_{\mathrm{V}}$ current and sustained $\mathrm{K}^{+}$(arrowhead) current. In current-clamp mode (Fig. 7B.1), depolarizing steps evoked transient responses (single spikes at step onset) in all complex calyces $(n=19)$, half of the simple calyces located in the striola ( 5 of 10), and one-third of the simple calyces located in the extrastriola (4 of 12). Sustained, regular spiking was evoked in 5 of 10 striolar and 8 of 12 extrastriolar simple calyces (Fig. 7B.2). In total, 24 of 29 striolar calyces and only 4 of 12 extrastriolar calyces had transient firing patterns. Together these results are consistent with previously reported correlations between the striolar zone, irregular firing, and transient firing patterns (Goldberg, 1991, Kalluri et al., 2010).

At $25-29^{\circ} \mathrm{C}$, spontaneous spiking occurred in just 1 of 19 complex striolar calyces recorded in current clamp. All 19 were capable of spiking, as revealed by injecting depolarizing current steps (Fig. 7B.1). Four of 10 simple striolar calyces fired spontaneously at $25-29^{\circ} \mathrm{C}$. The five spontaneously firing striolar calyces ( 1 complex and 4 simple) were all from P7 or P8 animals, raising the possibility that spike activity increases with maturation. They had irregular interspike intervals (Table 2), like striolar afferents in vivo (for review, see Goldberg, 2000).

In nine striolar calyces recorded at $35-37^{\circ} \mathrm{C}$, three of seven complex calyces and two of two simple calyces fired spontaneously (Fig. 7C.1, Table 2). Comparison of mean firing rates for the samples recorded at $25-29$ and $35-39^{\circ} \mathrm{C}$ yielded a $\mathrm{Q}_{10}$ temperature coefficient of 3 . As expected for striolar afferents in vivo, firing was irregular, and this was the case at both temperatures, with comparable coefficient of variation values $(\mathrm{SD} /$ mean) and Fano factors (variance/mean) [Fig. 7C.1, interspike interval (ISI) histogram; Table 2].

Relative to striolar calyces, extrastriolar calyces had significantly higher spontaneous rates and greater spike timing regularity at $25-29^{\circ} \mathrm{C}$ (Fig. 7C.2, ISI histogram; Table 2). The differences persisted when comparisons were made at similar spike rates, as illustrated by the examples in Figure $7 C$, suggesting that in vivo differences in spike regularity are preserved in our excised preparation. These differences may be related to frequency tuning if, as hypothesized (Sadeghi et al., 2007), spike regularity influences the frequency dependence of mutual information density in vestibular afferents.

Spike generation influences timing and tuning of afferent signals Experiments in which vestibular afferents were driven with sinusoidal extracellular currents suggested that spike-generating mechanisms do not contribute to the differences in response dynamics of regular and irregular afferents (Goldberg et al., 1982; Goldberg, 2000). For stimuli coming through the hair cell, however, we find that spike generation influences response dynamics, as illustrated in Figure 8. Fig. 8A,B shows EPSPs and spikes evoked in one calyx by sinusoidal hair-bundle displacements. EPSPs and spikes occurred together in Fig. 8A.2,A.3; in Figure $8 A .1$, EPSPs were isolated by hyperpolarizing the membrane below spike threshold. EPSPs at $<5 \mathrm{~Hz}$ and $>40 \mathrm{~Hz}$ were present but subthreshold; as a result, the tuning of spikes was sharper than the tuning of EPSPs. Comparing the timing of spikes and EPSPs (Fig. $8 B$ ) shows that spikes can cross threshold (arrowheads) or even peak before EPSPs peak (cyan arrows), producing a phase advance.

The frequency dependence of calyceal spiking is shown in Figure $8 C$, with gain plotted either as spikes/cycle/micrometer or as spikes/second/micrometer. The number and phase of spikes relative to hair-bundle displacement were averaged across five calyces for $\pm 300 \mathrm{~nm}$ displacements. The measurement of spikes/ cycle is more analogous to the measures we used at earlier stages ( $I_{\text {met }}$, RP, EPSC, and EPSP were all expressed as amplitude/cycle) but spikes/second is commonly used for in vivo afferent data. The direct comparison in Figure $8 C$ illustrates how normalizing by time (spikes/second) rather than stimulus cycle shifts the curve toward higher frequencies. Phase angle (timing relative to the stimulus) is the same in both cases. The averaged phase angle was high at low frequencies $\left(90^{\circ}\right.$ at $\left.2 \mathrm{~Hz}\right)$ but fell steeply with frequency, crossing zero to become a phase lag above $20 \mathrm{~Hz}$.

The transfer function between spike rate and EPSP amplitude (Fig. 8D, black circles), averaged over the same five calyces, directly shows the influence of spike-generating mechanisms. The tuning of gain by spike-generating mechanisms was stronger than can be shown because the $\sim 0$ spike rate below $5 \mathrm{~Hz}$ and above $40 \mathrm{~Hz}$ (Fig. 8A.2,A.3) cannot be represented on the logarithmic axis. In phase plots of spikes associated with the $f_{0}$ component of EPSPs (bottom graph, black circles), spikes had a large phase lead $\left(50^{\circ}\right.$ at $\left.5 \mathrm{~Hz}\right)$. If spike times are instead compared with the times of EPSP peaks (cyan circles; Fig. 6C, cyan arrows), spikes have a smaller but still substantial phase advance of $\sim 30^{\circ}$ at $5 \mathrm{~Hz}$, indicating that spikes can trigger during the rising phase of EPSPs. Thus, quantal transmission and the spike generator both contribute to the large phase advance of afferent spiking at low stimulus frequencies $(<40 \mathrm{~Hz})$.

For comparison, Figure $8 D$ includes (open triangles) the transfer function from postsynaptic potential to spike rate for the nonquantal synapse of Figure $5 B$. Spike rate was more sharply tuned and phase advanced relative to the nonquantal postsynaptic potential.

\section{Summary of tuning in immature striolar type I cells and calyces at room temperature}

Figure 9 summarizes the incremental loss of bandwidth as the mechanically evoked signal advances through the immature type I hair cell and calyceal terminal $\left(25-29^{\circ} \mathrm{C}\right)$. Stimuli were $\pm 600-$ $1000 \mathrm{~nm}$ displacements of the hair bundle, the larger of the two sinusoidal levels used in this study. Figure $9 A$ shows data from two exemplar cells, both striolar, $\mathrm{P} 7$, and recorded at $27^{\circ} \mathrm{C}$ : $I_{\text {met }}$ and RP are from a striolar type I cell in a double calyx, and EPSCs, EPSPs, and spikes are from the double calyx also featured in Figure $4 C$. Figure $9 B$ shows Bode plots of gain and phase of each signal referenced to the stimulus: calyceal data are from the exemplar calyx in $A$ and the $I_{\text {met }}$ and RP data are averaged data from several cells (replotted from Figs. $2 F$ and $3 C$, respectively). 
A Calyx EPSPs and spikes

P7 $27^{\circ} \mathrm{C}$
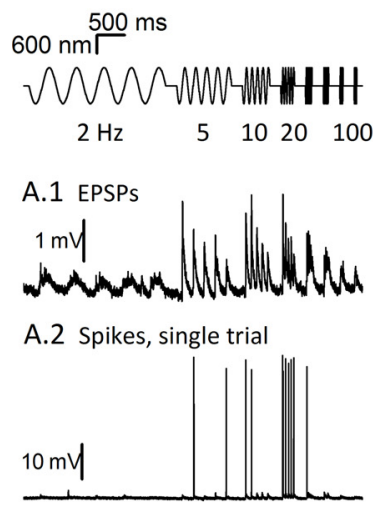

A.3 Spikes, 14 trials

$50 \mathrm{mV}$

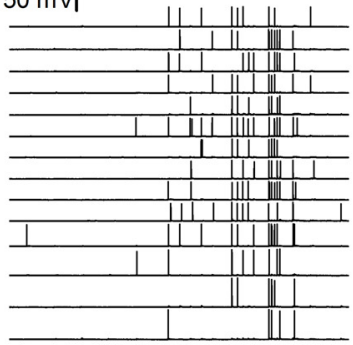

B EPSP vs. spike timing

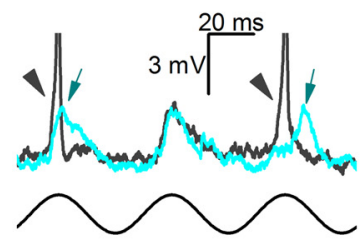

C spike tuning re: displacement

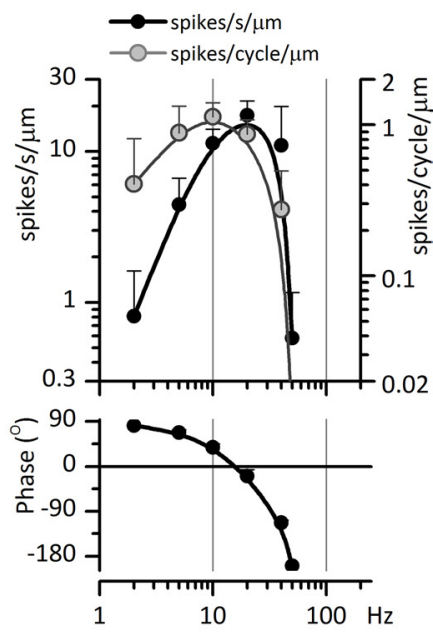

D Spike tuning re: EPSPs
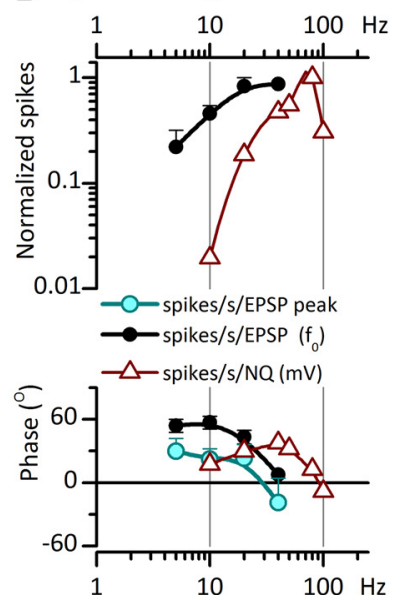

Figure 8. Spike generation sharpened tuning and increased phase lead (reduced latency) of the afferent signal. $\boldsymbol{A}, \boldsymbol{B}$, Current-clamp records from a striolar double calyx $\left(\mathrm{P} 7,27^{\circ} \mathrm{C}\right)$ during sinusoidal stimulation of one hair bundle. In sequence from the top are the $\pm 600 \mathrm{~nm}$ stimulus, (A.1) EPSPs averaged from three sweeps obtained without spikes from a resting potential of $-71 \mathrm{mV},($ A.2) a single trace showing spiking from the same cell (which began when the cell spontaneously depolarized to $-66 \mathrm{mV})$, (A.3) 14 sequential sweeps. Strong phase-locking produced near coincidence of spikes in different sweeps. The $20 \mathrm{~Hz}$ sinusoidal burst evoked the most spikes. $\boldsymbol{B}$, Two sweeps of the $20 \mathrm{~Hz}$ response at high temporal resolution, showing both spikes and EPSPs. As shown by arrows, spikes often precede the peaks of EPSPs (i.e., spikes phase-lead EPSPs at $20 \mathrm{~Hz}$ ). C, Gain and phase of spikes/cycle (gray circles) and spikes/second (black circles) referenced to bundle displacement expressed in micrometers. Averaged from five calyces, including the calyx in $\boldsymbol{A}$. The number of spikes per cycle is more analogous to the sizes of RPs, EPSCS, and EPSPs plotted in Figures 3 Cand $6 C$; the number of spikes per second can be compared with in vivo afferent data. $D$, Transfer functions for spikes/second referenced to EPSPs for the quantal data in C (solid black) and for the nonquantal (NQ) data in Figure $5 B$ (open brown triangles). By comparing spike rate with EPSPS, these plots show the additional tuning at the spike-generation stage; failure to trigger spikes at outlying frequencies significantly sharpens the spike-tuning curve. Bottom, Phase difference between spikes and EPSPs (spike phase minus EPSP phase), with EPSP phase measured in two ways for the quantal data: from the $f_{0}$ FFT component of EPSPs (black circles) or from the voltage peak (cyan circles; see $\boldsymbol{B}$, arrows). Below $30 \mathrm{~Hz}$, spikes had a substantial phase lead in either case, but thelead was smaller when peak EPSP was measured. For the nonquantal calyxin Figure $5 B$ (open brown triangles), spikes held a phase lead relative to the $f_{0}$ component of nonquantal postsynaptic potentials up to higher frequencies $(100 \mathrm{~Hz})$.

Best frequencies at each stage are between 10 and $50 \mathrm{~Hz}$. Lowfrequency gain and phase are strongly influenced by transducer adaptation, synapse adaptation, and spike generation. Highfrequency gain and phase are strongly influenced by the hair-cell

membrane charging time $\left(\tau_{\mathrm{m}}\right)$ and the delay across the synapse. For these relatively large stimuli, a single-pole filter with a corner frequency of $\left(1 / 2 \pi \tau_{\mathrm{m}}\right)$ closely approximates the transfer function of RP relative to $I_{\text {met; }}$; recall that smaller stimuli excite electrical resonance in the immature hair-cell membrane (Fig. 3), which sharpens RP tuning. A progressive phase lag accumulates at high frequencies. The phase lag of EPSCs relative to RP suggests a $3 \mathrm{~ms}$ synaptic delay (Fig. $6 D$ ). In this exemplar calyx, the quantal response was prominent (Fig. 9A), and the timing data (Fig. 4C.4, step latencies; Fig. 9B, phase data) suggest that any nonquantal component was not significant.

\section{Maturation and physiological temperature affect tuning and timing of the receptor potential}

The strong low-pass filtering of the receptor potential by the membrane of immature type I hair cells depends on their high input resistances. It is well known, however, that as type I cells mature, they acquire large numbers of low-voltage-activated $\mathrm{K}$ channels, collectively called $g_{\mathrm{K}, \mathrm{L}}$, which reduce $R_{\text {in }}$ and electrical tuning (Correia and Lang, 1990; subsequent publications are reviewed in Eatock and Songer, 2011). In this section we show how $g_{\mathrm{K}, \mathrm{L}}$ changed hair-cell tuning and timing.

Striolar type I hair cells in the rat saccule gradually acquire $g_{\mathrm{K}, \mathrm{L}}$ with age, as previously described for the utricles of mice (Rüsch et al., 1998; Géléoc et al., 2004) and rats (Hurley et al., 2006). Figure 10 compares voltage-gated currents $(A)$ and conductance-voltage curves $(B)$ in exemplar $\mathrm{P} 2$ and $\mathrm{P} 7-\mathrm{P} 8$ striolar type I cells at $25-29^{\circ} \mathrm{C}$ (“2 $7^{\circ} \mathrm{C}$ ”) and $35-39^{\circ} \mathrm{C}$ (“ $37^{\circ} \mathrm{C}$ "). P7-P8 cells had a large conductance $\left(g_{\mathrm{K}, \mathrm{L}}\right)$ at the holding potential of $-65 \mathrm{mV}$, which was deactivated by stepping to $-125 \mathrm{mV}$, then reactivated with steps positive to $-100 \mathrm{mV}$ (Fig. 10 A). In contrast, the $\mathrm{K}^{+}$conductance of $\mathrm{P} 2$ cells activated positive to resting potential and was much smaller (Fig. 10A). $G(\mathrm{~V})$ curves in Figure $10 \mathrm{~B}$ illustrate the large difference in steady-state activation ranges and maximum conductance at the two ages. Between P3 and P9, the average half-activation value in a sample of 63 striolar type I cells fell from $\sim-30$ to $\sim-70 \mathrm{mV}$ and $g_{\max }$ tripled. Table 3 shows strong effects of age (P2-P4 vs P7-P9) on activation midpoint, maximal conductance, and activation kinetics, which is accounted for by the acquisition of $g_{\mathrm{K}, \mathrm{L}}$.

Figure 10 also shows the effect of increasing temperature on activation of outward currents, as illustrated with activation curves (Fig. 10 B, Table 3) and activation time course (Fig. 10C, Table 3). In contrast to a previous report on mouse utricular type I hair cells (Rüsch and Eatock, 1996), we found no significant temperature-induced shift in steady-state activation at either age. In the previous study, individual cells were followed as temperature was shifted, whereas we are comparing two populations held at different temperatures. Monoexponential fits of the current evoked by a step from -125 to $-35 \mathrm{mV}$ yielded activation time constants $\left(\tau_{\mathrm{K}}\right)$ with mean values that decreased at higher temperatures (Fig. 10C) with a thermal coefficient of 1.6-1.7 (calculated from values in Table 3 ).

Adding $g_{\mathrm{K}, \mathrm{L}}$ and increasing temperature had a dramatic combined effect on receptor potentials, as illustrated in Figure $10 \mathrm{D}$ for one type I cell responding to sinusoidal displacements. The $\mathrm{RP}$ was much smaller and less tuned than for type I cells lacking $g_{\mathrm{K}, \mathrm{L}}$ and at $27^{\circ} \mathrm{C}$ (Fig. $3 A$ ). These effects are quantified and averaged across several cells in Bode plots (Fig. 10E). Striolar type I cells without $g_{\mathrm{K}, \mathrm{L}}$ at $25-29^{\circ} \mathrm{C}$ (blue filled circles) had larger gains than striolar type I cells with $g_{\mathrm{K}, \mathrm{L}}$ at mammalian temperature (red triangles) and had much larger phase lags above $2 \mathrm{~Hz}$. Thus, the combination of higher temperature and $g_{\mathrm{K}, \mathrm{L}}$ flattened tuning and 
A

$1 \mu \mathrm{m} \overbrace{2 \mathrm{~Hz}}^{1 \mathrm{~s}} \sim_{5}{ }_{10}{ }_{20}{ }_{100}$

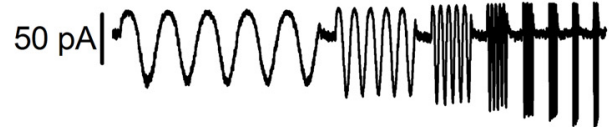

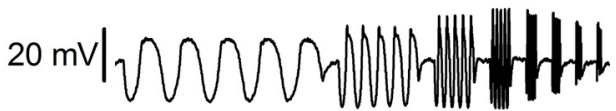

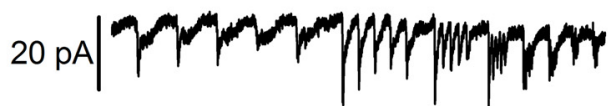

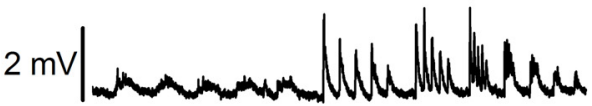

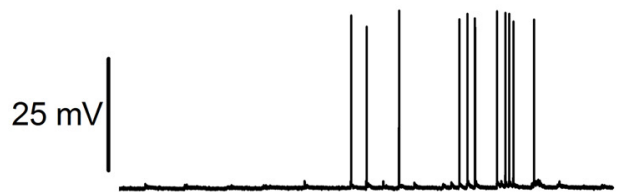

B
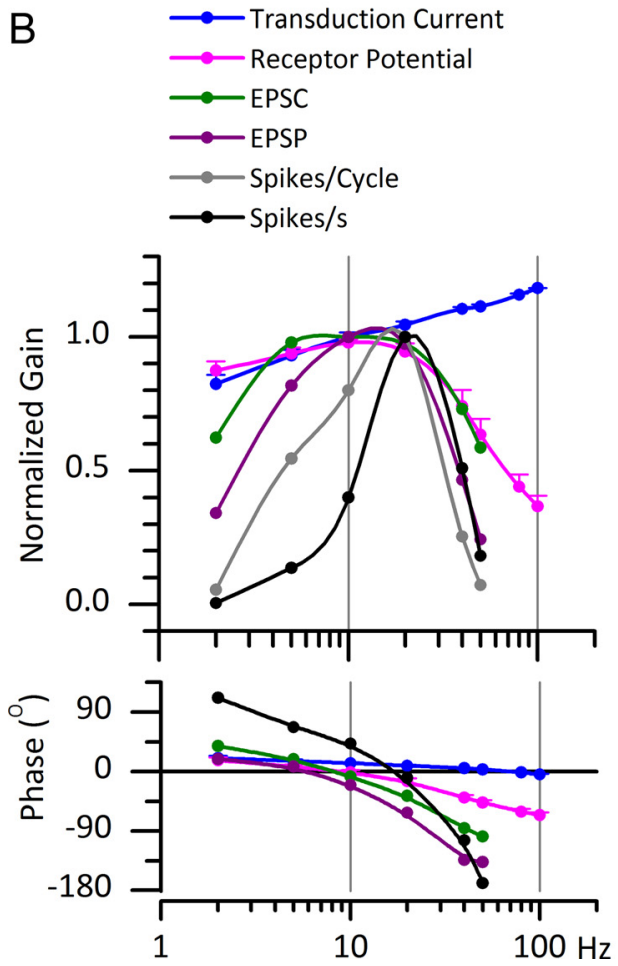

Figure 9. Summary of tuning by type I hair cells and calyces in the rat saccular epithelium (P2-P9) for $\pm 600-1000 \mathrm{~nm}$ stimuli at $25-29^{\circ} \mathrm{C}$. Gains are normalized by the peak response. The type I cell data summarized here were immature in that they lacked the signature conductance of mature type I cells, $g_{K, L}$ (Fig. 10). Tuning got progressively sharper as the signal advanced from the transduction channels to the afferent spike generator. $A$, Exemplar responses to sinusoidal bursts are aligned for a type I hair cell from a complex calyx $\left(I_{\text {met }}\right.$ and RP) and for a double calyx (EPSCS, EPSPs, and spikes); both cells were from P7 striolar zones and recorded at $27^{\circ} \mathrm{C}$. From top to bottom: Sinusoidal bursts $(2,5,10,20,40,50,80$, and $100 \mathrm{~Hz}), I_{\text {met, }} R P$, EPSCS, EPSPS, and spikes. $\boldsymbol{B}$, Response gain and phase referenced to bundle displacement. Hair-cell data $\left(I_{\text {met }}, R P\right)$ are the same averaged data shown in Figure 3C. Calyx data (EPSC, EPSP, spikes/ cycle, and spikes/second) are from the exemplar calyx of $\boldsymbol{A}$. FFTs were used to calculate gains and phases at each stage except spiking. strongly increased phase over most of the frequency range. A significant effect of $g_{\mathrm{K}, \mathrm{L}}$ alone is predicted by its well known effect on low-pass corner frequency (Correia et al., 1996), and individual examples support this prediction. In Figure $10 E$, data from two cells at the same temperature $\left(27^{\circ} \mathrm{C}\right.$ ), one with $g_{\mathrm{K}, \mathrm{L}}$ (cyan triangles) and one without $g_{\mathrm{K}, \mathrm{L}}$ (blue open circles), suggest that $g_{\mathrm{K}, \mathrm{L}}$ may decrease gain $\sim 5$-fold and increase the low-pass corner frequency $\sim 10$-fold. Cells with $g_{\mathrm{K}, \mathrm{L}}$ also, as expected, lacked electrical resonance (data not shown).

Thus, by inserting many low-voltage-activated channels in its membrane, the developing type I hair cell sacrifices gain and sharpness of electrical tuning in return for faster timing. This maturational specialization is consistent with the known emphasis of striolar and central zones of vestibular epithelia on phasic signals and high conduction velocity (Goldberg, 1991).

\section{Discussion}

In immature saccular epithelia, tuning was typically centered between 10 and $50 \mathrm{~Hz}$ and sharpened at each afferent stage (Fig. 9). Electrical tuning was a prominent feature of the receptor potential at small stimulus levels (Fig. 3). Thus, immature vestibular hair cells, like immature cochlear hair cells (Kennedy, 2012), have mechanisms to amplify small mechanoelectrical signals at early stages of development. With maturation, type I cells lose gain but add bandwidth and speed, possibly reflecting a need to supply fast, linear representations of head motions to reflex pathways.

VORs can have near ideal performance over a wide frequency range. For head-motion frequencies from $<5$ to $\geq 25 \mathrm{~Hz}$, the angular VOR has a gain (eye motion per head motion) near 1 and phase near zero (Huterer and Cullen, 2002). This reflex pathway involves four synapses from hair cell to ocular muscle. The flat frequency performance of the reflex requires that neurobiological mechanisms introduce phase leads to compensate for phase lags incurred by conduction and transmission times along the pathway. We have identified several inner-ear mechanisms that advance response phase: adaptation of mechanoelectrical transduction, addition of $\mathrm{K}_{\mathrm{LV}}$ channels to the hair-cell membrane, nonquantal transmission, and spike generation in the primary afferent terminal. Although the angular VOR is mediated by semicircular canals, our saccular data are relevant given the striking morphological and physiological parallels between canals and otolith organs (Goldberg, 1991; Eatock and Songer, 2011). In vivo data from mature vestibular afferents (Hullar et al., 2005; Ramachandran and Lisberger, 2006; Lasker et al., 2008) show high-pass filtering for frequencies up to $20 \mathrm{~Hz}$ or more, which is qualitatively consistent with our data. Maturational changes in the calyx may further enhance response speed: striolar calyces, like type I hair cells, add $\mathrm{K}_{\mathrm{LV}}$ channels past the first postnatal week (Hurley et al., 2006; Kalluri et al., 2010).

\section{Mechanoelectrical adaptation}

In mammalian cochlear hair cells, reducing external $\mathrm{Ca}^{2+}$ from perilymph levels (millimolar) to the low levels in mature cochlear endolymph $(20 \mu \mathrm{M})$ doubled adaptation time constants (Beurg et al., 2010). The smaller difference between mature vestibular endolymphatic levels [ 200-250 $\mu \mathrm{M}$ (Sterkers et al., 1988)] and our external $\mathrm{Ca}^{2+}(1.3 \mathrm{~mm})$ should have a smaller impact on adaptation time constants. These considerations and our results suggest that, at physiological $\mathrm{Ca}^{2+}$ and body temperature, transducer adaptation in mammalian vestibular hair cells may have time constants of 50-100 and 5-10 ms, with corresponding highpass corner frequencies of $1-3$ and $15-30 \mathrm{~Hz}$, well positioned to influence vestibular signals. An important effect of adaptation is 
A Type I $\mathrm{K}^{+}$current
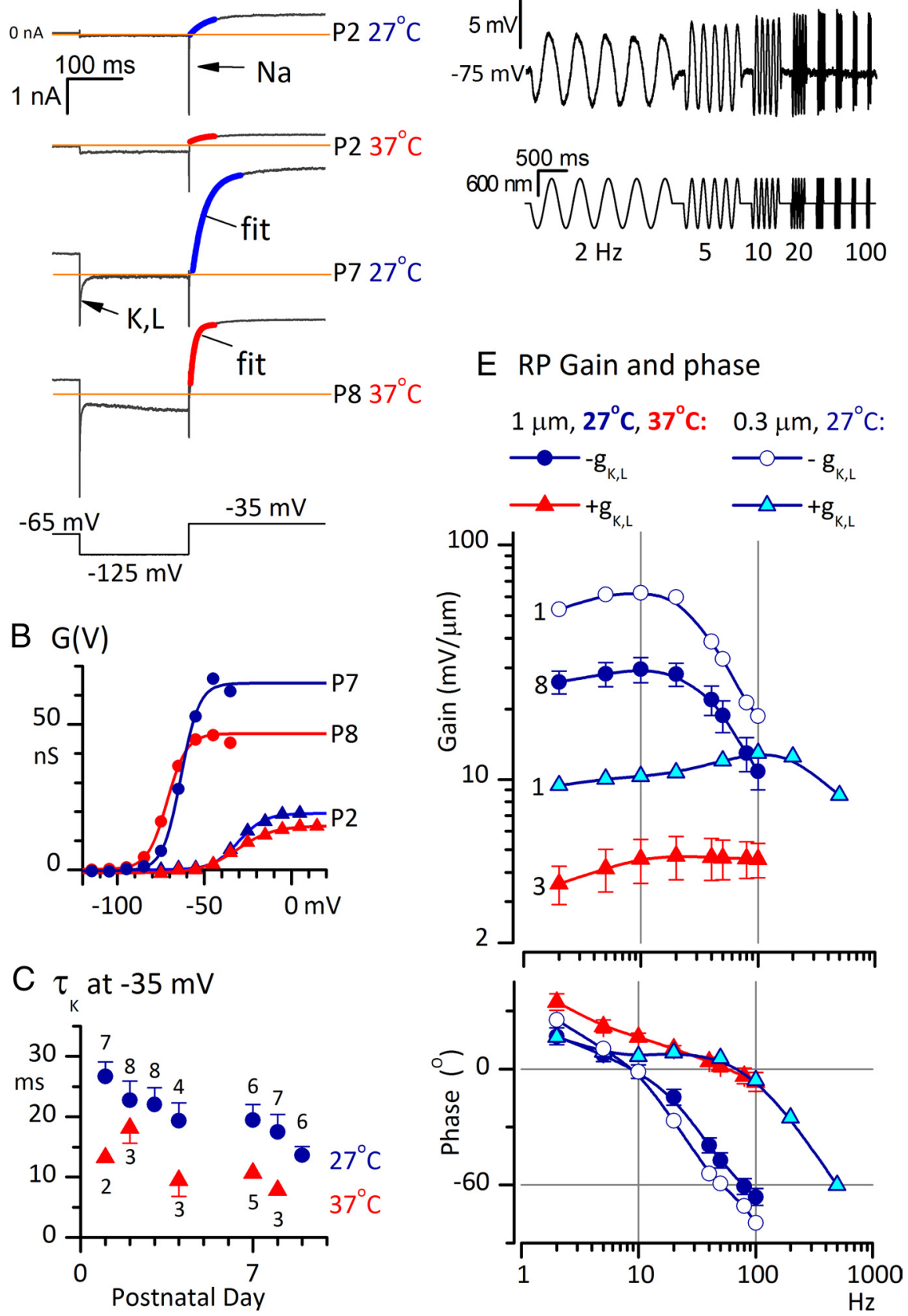

Figure 10. Acquisition of $g_{K, L}$ by striolar type I hair cells in the first postnatal week greatly broadened receptor potential tuning and reduced phase lags above $5 \mathrm{~Hz}$. A-C, Acquisition of $g_{\mathrm{K}, \mathrm{L}}$ with age; effects of temperature. $A$, Currents evoked in four type I hair cells by the same voltage protocol (bottom). At P2 (both 27 and $37^{\circ} \mathrm{C}$ ), the step from -125 to $-35 \mathrm{mV}$ evoked a fast $\mathrm{Na}^{+}$current and an outward current that activated positive to resting potential, as shown by activation curves in B. At P7-P8, type I hair cells had a $\mathrm{K}^{+}$conductance, $g_{\mathrm{K}, \mathrm{l}}$, which was activated at $-65 \mathrm{mV}$, deactivated (arrow, P7 trace) during the step to $-125 \mathrm{mV}$, and reactivated during the step to $-35 \mathrm{mV}$. Colored curves are monoexponential fits to activation. Note the faster activation at $37^{\circ} \mathrm{C}$. In the P8 trace (bottom), the gradual increase in inward current during the $-125 \mathrm{mV}$ step reflects activation of HCN channels. $\boldsymbol{B}$, Conductance-voltage ( $G(V)$ or activation) curves generated from outward tail currents at $-35 \mathrm{mV}$, as described in Materials and Methods, for the four cells in $\boldsymbol{A}$. At P2, conductances activated positive to resting potential; at P7-P8, conductances activated negative to resting potential. See Table 3 for average parameters from Boltzmann fits to $G(V)$ curves. $C$, Activation kinetics of $K^{+}$ current as functions of age and temperature. $\tau$ values are from exponential fits of currents evoked by stepping from -125 to -35 $\mathrm{mV}$, as shown in $A$. N's of averages are shown next to symbols. As activation shifted negatively with age, $\tau_{\mathrm{K}}$ at $-35 \mathrm{mV}$ decreased. Increasing temperature by $10^{\circ} \mathrm{C}$ to $37^{\circ} \mathrm{C}$ also significantly reduced $\tau_{\mathrm{K}}$ at $-35 \mathrm{mV}$. D, RP from a type I cell with $g_{\mathrm{K}, \mathrm{L}^{\prime}} \mathrm{P} 8,37^{\circ} \mathrm{C}(10$ traces averaged) in response to $\pm 600 \mathrm{~nm}$ sinusoidal bursts. Compared with RP in immature type I cells to similar stimuli (Fig. $3 \mathrm{~A}$ ), $\mathrm{RP}$ in cells with $g_{\mathrm{K}, \mathrm{L}}$ was smaller and had a broader bandwidth (did not decrease with frequency, at least up to $100 \mathrm{~Hz}$ ). $E$, Effects of $g_{\mathrm{K}, \mathrm{L}}$ and temperature on gain and phase of RP referenced to bundle displacement. Numbers of cells used for each curve are shown to the left of each gain curve. Cells with $g_{K, L}$ at $37^{\circ} \mathrm{C}(r e d)$ had much lower gains and greater phase leads than cells without $g_{K, L}$ at $27^{\circ} \mathrm{C}$ the phase lead in $I_{\text {met }}$ relative to bundle displacement at frequencies of $<100 \mathrm{~Hz}$ $\left(35-39^{\circ} \mathrm{C}\right)$.

\section{Voltage responses of striolar type I hair cells}

Frog saccular and turtle cochlear hair cells have high-quality electrical resonances that support tuning to vibrations and sound, respectively (Art and Fettiplace, 1987; Hudspeth and Lewis, 1988; Catacuzzeno et al., 2004). Here we report that immature striolar type I cells from the rat saccule also have sharp $\left(Q_{e}>5\right)$ electrical tuning matched to the mechanical tuning of the receptor potential (Fig. 3). Like other immature hair cells in rodents (Rüsch and Eatock, 1997; Marcotti et al., 2003; Géléoc et al., 2004; Wooltorton et al., 2007), immature striolar type I cells of the rat saccule have sizeable $\mathrm{Na}_{\mathrm{V}}$ conductances (Fig. 10A), which may contribute to electrical tuning or spiking, as in cochlear hair cells (Marcotti et al., 2003). The enhanced excitability of immature hair cells is thought to drive development of the immature auditory and vestibular systems (Kennedy, 2012). In preparation for mature function, neonatal striolar type I hair cells lose $\mathrm{Na}_{\mathrm{V}}$ channels (Géléoc et al., 2004; Wooltorton et al., 2007) and gain $g_{\mathrm{K}, \mathrm{L}}$ (Fig. 10) and consequently are no longer electrically resonant. The impact of $g_{\mathrm{K}, \mathrm{L}}$ on tuning and timing of the RP is expected to be felt at downstream stages, but this remains to be demonstrated.

$\mathrm{K}_{\mathrm{LV}}$ channels in neurons reduce response times (Rothman and Manis, 2003), but the rationale for $g_{\mathrm{K}, \mathrm{L}}$ in vestibular hair cells has not been clear. If most head-motion energy is at frequencies $<10$ $\mathrm{Hz}$, membrane-charging times in hair cells without $g_{\mathrm{K}, \mathrm{L}}$ (type II cells) should suffice. Why add $g_{\mathrm{K}, \mathrm{L}}$ and suffer the reduced gain? The answer may be that natural stimuli do include frequencies well above $10 \mathrm{~Hz}$ (Armand and Minor, 2001). Otolith striolar afferents respond to bone vibrations (Curthoys and Vulovic, 2011), phase-lock to acoustic tones at hundreds

\footnotetext{
(dark blue circles). Gains were higher for small stimuli than for large stimuli (compare open circles and dark blue circles), as expected from the saturation of $V_{m}(X)$ relations (Fig. 3E). Extending the frequency range for a cell with $g_{\mathrm{K}, \mathrm{L}}$ at $27^{\circ} \mathrm{C}$ (cyan triangles) revealed the large increase in low-pass corner frequency relative to cells without $g_{\mathrm{K}, \mathrm{L}}$ at $27^{\circ} \mathrm{C}$ (compare with open circles for same stimulus size and temperature). Bottom, Phase plots. In cells lacking $g_{K, L}$ (open and filled circles), RP lagged bundle displacement (phase was negative) for frequencies $>10 \mathrm{~Hz}$; in cells with $g_{\mathrm{K}, L}$ (red and cyan triangles), RP led displacement (phase was positive) up to almost $100 \mathrm{~Hz}$.
} 
Table 3. Changes in electrophysiological parameters of striolar type I hair cells with age and temperature

\begin{tabular}{|c|c|c|c|c|c|c|c|c|c|c|c|c|c|}
\hline \multirow[b]{3}{*}{ Temperature } & \multirow[b]{3}{*}{$t$ test } & \multicolumn{4}{|c|}{ Membrane properties } & \multicolumn{6}{|c|}{ Boltzmann parameters of activation } & & \\
\hline & & \multicolumn{2}{|l|}{$R_{\mathrm{m}}(\mathrm{M} \Omega)$} & \multicolumn{2}{|l|}{$c_{m}(\mathrm{pF})$} & \multicolumn{2}{|l|}{$V_{1 / 2}(\mathrm{mV})$} & \multicolumn{2}{|c|}{$g_{\mathrm{K}}(\mathrm{nS}),-35 \mathrm{mV}$} & \multicolumn{2}{|l|}{$S(\mathrm{mV})$} & \multicolumn{2}{|c|}{$\tau_{\mathrm{k}},-35 \mathrm{mV}(\mathrm{ms})$} \\
\hline & & P1-P4 & P7-P9 & P1-P4 & P7-P9 & P1-P4 & P7-P9 & P1-P4 & P7-P9 & P1-P4 & P7-P9 & P1-P4 & P7-P9 \\
\hline \multirow[t]{2}{*}{$27^{\circ} \mathrm{C}$} & & $899 \pm 202(16)$ & $294 \pm 100(17)$ & $7.7 \pm 0.2(16)$ & $7.3 \pm 0.5(17)$ & $-35 \pm 2(27)$ & $-63 \pm 4(19)$ & $16 \pm 1(27)$ & $35 \pm 5(19)$ & $9.4 \pm 0.4(27)$ & $8.2 \pm 0.5(19)$ & $23 \pm 1(27)$ & $17 \pm 1(19)$ \\
\hline & Age effect, $p$ value & \multicolumn{2}{|c|}{$<0.01^{a}$} & \multicolumn{2}{|c|}{ NS } & \multicolumn{2}{|c|}{$<1 \mathrm{e}-8^{b}$} & \multicolumn{2}{|c|}{$<4 \mathrm{e}-4^{c}$} & \multicolumn{2}{|c|}{ NS } & \multicolumn{2}{|c|}{$<0.01^{d}$} \\
\hline \multirow[t]{3}{*}{$37^{\circ} \mathrm{C}$} & & $570 \pm 128(7)$ & $54 \pm 17(5)$ & $8.3 \pm 0.3(7)$ & $8.9 \pm 0.2(2)$ & $-39 \pm 4(9)$ & $-62 \pm 5(8)$ & $17 \pm 1(9)$ & $39 \pm 9(8)$ & $9.3 \pm 0.5(9)$ & $7.8 \pm 0.4(8)$ & $14 \pm 2(9)$ & $10 \pm 2(8)$ \\
\hline & Age effect, $p$ value & \multicolumn{2}{|c|}{$<0.02^{a}$} & \multicolumn{2}{|c|}{ NS } & \multicolumn{2}{|c|}{$<7 \mathrm{e}-3^{b}$} & \multicolumn{2}{|c|}{$<0.01^{c}$} & \multicolumn{2}{|c|}{ NS } & \multicolumn{2}{|c|}{ NS } \\
\hline & Temperature effect & NS & NS & NS & NS & NS & NS & NS & NS & NS & NS & $<4 \mathrm{e}-3^{e}$ & $<0.05$ \\
\hline
\end{tabular}

Significance was tested with one-way ANOVA; differences were considered significant at $p<0.05$ and are provided when significant. NS, not significant. The reduced $R_{\mathrm{m}}{ }^{a}$, more negative $V_{1 / 2}{ }^{b}$, increased maximum $g_{\mathrm{K}}{ }^{c}$, and decreased activation time course of outward current at $-35 \mathrm{mV}\left(\tau_{\mathrm{K}}\right)^{d}$ of P4-P7 cells reflect the increased expression of $g_{\mathrm{K}, \mathrm{L}}$. Increasing temperature also decreased $\tau_{\mathrm{K}}{ }^{e}$.

of hertz (McCue and Guinan, 1994), and have remarkably short acoustic latencies, as discussed in the next section. These capabilities may require the improvement in RP response time that accompanies $g_{\mathrm{K}, \mathrm{L}}$ (Fig. $10 \mathrm{E}$ ).

\section{Synaptic transmission}

The envelopment of type I hair cells by the vestibular calyx has long prompted interest in the possibility of nonquantal transmission. Given the abundant evidence for quantal transmission at these synapses (e.g., Lysakowski and Goldberg, 1997, Schessel et al., 1991; Bonsacquet et al., 2006; Rennie and Streeter, 2006; Dulon et al., 2009), any nonquantal transmission must coexist with quantal mechanisms. We provide evidence for both. The graded responses illustrated in Figure 5 are unlikely to reflect the summation of quanta, based on their short latencies, the absence of individual quanta, and hyperpolarizing responses to negative bundle deflections.

The mechanism of nonquantal transmission is not known. Fluorescent dye did not pass between hair cell and calyx in our experiments, consistent with earlier evidence that gap junctions are not involved (Gulley and Bagger-Sjöbäck, 1979; Ginzberg, 1984; Yamashita and Ohmori, 1991). Pharmacological experiments on turtle crista afferents suggest that only a minor component of nonquantal activity is attributable to glutamate accumulation (Holt et al., 2007). Other possibilities include ephaptic transmission and $\mathrm{K}^{+}$changes in the synaptic cleft (Goldberg, 1996; Lim et al., 2011; Contini et al., 2012).

In recordings from afferent fibers at sites distant from the terminals and stimulated by cupular motion (Holt et al., 2007), quantal and nonquantal components occur together, but might arise at different afferent terminals. Our methods revealed that nonquantal responses alone can trigger spikes (Fig. $5 B$ ) and that both quantal and nonquantal components can be present within individual calyces (Fig. 5C). Given that an individual calyx can generate both kinds of responses, the difference in transmission modes may have a presynaptic origin, such as a difference in hair-cell ion channels. Type I hair cells may acquire $g_{\mathrm{K}, \mathrm{L}}$ channels (Fig. 10) at different rates or differentially express BK (big potassium) channels (Schweizer et al., 2009). Nonquantal transmission could be an immature property in our tissue but it also occurs in more mature calyx-bearing afferents of turtles (Holt et al., 2007) and chicks (Yamashita and Ohmori, 1990).

Nonquantal transmission may reduce response latency (Figs. 5, 6D). Quantal synaptic delays, which averaged $3-4 \mathrm{~ms}$ at $27^{\circ} \mathrm{C}$ (Figs. $4 B, 8 D$ ), are likely to be much reduced at body temperature and following maturation, as demonstrated at other synapses (Wang et al., 2009). Nevertheless, for striolar afferents in the cat saccular nerve, estimated synaptic delays to loud acoustic clicks ( $\sim 300 \mu \mathrm{s}$; McCue and Guinan, 1994) are even shorter than cochlear delays, leading McCue and Guinan (1994) to speculate that transmission at the type I-calyx synapse is electrical (i.e., nonquantal). While nonquantal transmission is fast, quantal transmission affords amplification via biochemical cascades, one-way directionality, and tuning (amplification at frequencies of interest) (Schnee et al., 2005; Rutherford and Roberts, 2006). Having both mechanisms could make calyceal transmission more versatile through differences in their level and frequency dependence or in their sensitivity to transmitters released from efferent terminals on calyces.

\section{Afferent spiking}

Differences in response dynamics of striolar and extrastriolar afferents (Goldberg et al., 1990a) have previously been attributed to mechanical and hair-cell stages, whereas differences in spike timing were attributed to afferent properties (Goldberg, 2000). We observed, however, that postsynaptic spike-generating mechanisms in the afferent sharpened tuning and enhanced phase leads relative to EPSPs. Thus, differences in ion-channel expression between central-zone and peripheral-zone calyces (Lysakowski et al., 2011) may contribute to zonal differences in afferent response dynamics.

The phase leads of afferent spikes relative to bundle displacement plateaued near $+80^{\circ}$ at $2 \mathrm{~Hz}$ (Fig. $8 \mathrm{C}$ ), higher than phase leads $\left(\sim 45^{\circ}\right)$ of vestibular afferents relative to head motion at 2 $\mathrm{Hz}$ (Goldberg et al., 1990b; Lasker et al., 2008). Factors in this difference might include the transformation from head motion to bundle deflection and differences in developmental stage and $\mathrm{Ca}^{2+}$ levels.

Recordings from isolated parent cell bodies of vestibular afferents suggested that the irregular firing of striolar afferents requires $\mathrm{K}_{\mathrm{LV}}$ channels (Kalluri et al., 2010); this hypothesis assumed that ion channels in the cell bodies resemble those at spike initiation zones in distal afferent terminals. In the striola, spiking is likely to initiate at the afferent heminode immediately below the calyx, and both the calyx and heminodes are strongly immunoreactive for $\mathrm{K}_{\mathrm{LV}}$ subunits from the $\mathrm{K}_{\mathrm{V}} 1$ and $\mathrm{K}_{\mathrm{V}} 7$ channel families (Lysakowski et al., 2011). Our evidence for $\mathrm{K}_{\mathrm{LV}}$ current and irregular spiking in striolar calyces (Fig. 7) strengthens the evidence linking striolar irregular spike timing to $\mathrm{K}_{\mathrm{LV}}$ channel expression.

\section{References}

Armand M, Minor LB (2001) Relationship between time- and frequencydomain analyses of angular head movements in the squirrel monkey. J Comput Neurosci 11:217-239. CrossRef Medline

Art JJ, Fettiplace R (1987) Variation of membrane properties in hair cells isolated from the turtle cochlea. J Physiol 385:207-242. Medline

Baird RA, Desmadryl G, Fernández C, Goldberg JM (1988) The vestibular nerve of the chinchilla. II. Relation between afferent response properties and peripheral innervation patterns in the semicircular canals. J Neurophysiol 60:182-203. Medline

Barry PH (1994) JPCalc, a software package for calculating liquid junction potential corrections in patch-clamp, intracellular, epithelial and bilayer 
measurements and for correcting junction potential measurements. J Neurosci Methods 51:107-116. Medline

Beurg M, Nam JH, Chen Q, Fettiplace R (2010) Calcium balance and mechanotransduction in rat cochlear hair cells. J Neurophysiol 104:1834. CrossRef Medline

Bonsacquet J, Brugeaud A, Compan V, Desmadryl G, Chabbert C (2006) AMPA type glutamate receptor mediates neurotransmission at turtle vestibular calyx synapse. J Physiol 576:63-71. CrossRef Medline

Catacuzzeno L, Fioretti B, Perin P, Franciolini F (2004) Spontaneous lowfrequency voltage oscillations in frog saccular hair cells. J Physiol 561: 685-701. CrossRef Medline

Cherif S, Cullen KE, Galiana HL (2008) An improved method for the estimation of firing rate dynamics using an optimal digital filter. J Neurosci Methods 173:165-181. Medline

Contini D, Zampini V, Tavazzani E, Magistretti J, Russo G, Prigioni I, Masetto S (2012) Intercellular K+ accumulation depolarizes type I vestibular hair and their associated afferent nerve calyx. Neuroscience 227: 232-246. CrossRef Medline

Corey DP, Hudspeth AJ (1980) Mechanical stimulation and micromanipulation with piezoelectric bimorph elements. J Neurosci Methods 3:183202. Medline

Correia MJ, Lang DG (1990) An electrophysiological comparison of solitary type I and type II vestibular hair cells. Neurosci Lett 116:106-111. CrossRef Medline

Correia MJ, Ricci AJ, Rennie KJ (1996) Filtering properties of vestibular hair cells: An update. Ann NY Acad Sci 781:138-149. CrossRef Medline

Crawford AC, Fettiplace R (1981) An electrical tuning mechanism in turtle cochlear hair cells. J Physiol 312:377-412. Medline

Curthoys IS (1983) The development of function of primary vestibular neurons. In: Development of auditory and vestibular systems (Romand R, ed), pp 425-461. New York: Academic.

Curthoys IS, Vulovic V (2011) Vestibular primary afferent responses to sound and vibration in the guinea pig. Exp Brain Res 210:347-352. CrossRef Medline

Dulon D, Safieddine S, Jones SM, Petit C (2009) Otoferlin is critical for a highly sensitive and linear calcium-dependent exocytosis at vestibular hair cell ribbon synapses. J Neurosci 29:10474-10487. CrossRef Medline

Eatock RA (2000) Adaptation in hair cells. Annu Rev Neurosci 23:285-314. CrossRef Medline

Eatock RA, Songer JE (2011) Vestibular hair cells and afferents: two channels for head motion signals. Annu Rev Neurosci 34:501-534. CrossRef Medline

Eatock RA, Weiss TF, Otto KL (1991) Dependence of discharge rate on sound pressure level in cochlear nerve fibers of the alligator lizard: implications for cochlear mechanisms. J Neurophysiol 65:1580-1597. Medline

Fernández C, Goldberg JM (1976) Physiology of peripheral neurons innervating otolith organs of the squirrel monkey. III. Response dynamics. J Neurophysiol 39:996-1008. Medline

Fettiplace R, Hackney CM (2006) The sensory and motor roles of auditory hair cells. Nat Rev Neurosci 7:19-29. CrossRef Medline

Géléoc GS, Holt JR (2003) Developmental acquisition of sensory transduction in hair cells of the mouse inner ear. Nat Neurosci 6:1019-1020. CrossRef Medline

Géléoc GS, Risner JR, Holt JR (2004) Developmental acquisition of voltagedependent conductances and sensory signaling in hair cells of the embryonic mouse inner ear. J Neurosci 24:11148-11159. CrossRef Medline

Ginzberg RD (1984) Freeze-fracture morphology of the vestibular hiar cellprimary afferent synapse in the chick. J Neurocytol 13:393-405. CrossRef Medline

Goldberg JM (1991) The vestibular end organs: morphological and physiological diversity of afferents. Curr Opin Neurobiol 1:229-235. CrossRef Medline

Goldberg JM (1996) A theoretical analysis of intercellular communication between the vestibular type I hair cell and its calyx ending. J Neurophysiol 76:1942-1957. Medline

Goldberg JM (2000) Afferent diversity and the organization of central vestibular pathways. Exp Brain Res 130:277-297. CrossRef Medline

Goldberg JM, Fernández C (1977) Conduction times and background discharge of vestibular afferents. Brain Res 122:545-550. CrossRef Medline

Goldberg JM, Fernández C, Smith CE (1982) Responses of vestibular-nerve afferents in the squirrel monkey to externally applied galvanic currents. Brain Res 252:156-160. CrossRef Medline
Goldberg JM, Desmadryl G, Baird RA, Fernández C (1990a) The vestibular nerve of the chinchilla. V. Relation between afferent discharge properties and peripheral innervation patterns in the utricular macula. J Neurophysiol 63:791-804. Medline

Goldberg JM, Desmadryl G, Baird RA, Fernández C (1990b) The vestibular nerve of the chinchilla. IV. Discharge properties of utricular afferents. J Neurophysiol 63:781-790. Medline

Goutman JD, Glowatzki E (2007) Time course and calcium dependence of transmitter release at a single ribbon synapse. Proc Natl Acad Sci U S A 104:16341-16346. CrossRef Medline

Grant L, Yi E, Glowatzki E (2010) Two modes of release shape the postsynaptic response at the inner hair cell ribbon synapse. J Neurosci 30:42104220. CrossRef Medline

Gulley RL, Bagger-Sjöbäck D (1979) Freeze-fracture studies on the synapse between the type I hair cell an the calyceal terminal in the guinea-pig vestibular system. J Neurocytol 8:591-603. CrossRef Medline

Holt JC, Chatlani S, Lysakowski A, Goldberg JM (2007) Quantal and nonquantal transmission in calyx-bearing fibers of the turtle posterior crista. J Neurophysiol 98:1083-1101. CrossRef Medline

Hudspeth AJ, Lewis RS (1988) A model for electrical resonance and frequency tuning in saccular hair cells of the bull-frog, Rana catesbeiana. J Physiol 400:275-297. Medline

Hullar TE, Della Santina CC, Hirvonen T, Lasker DM, Carey JP, Minor LB (2005) Responses of irregularly discharging chinchilla semicircular canal vestibular-nerve afferents during high-frequency head rotations. J Neurophysiol 93:2777-2786. CrossRef Medline

Hurley KM, Gaboyard S, Zhong M, Price SD, Wooltorton JR, Lysakowski A,

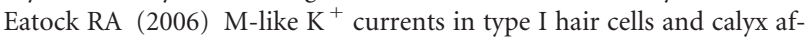
ferent endings of the developing rat utricle. J Neurosci 26:10253-10269. CrossRef Medline

Huterer M, Cullen KE (2002) Vestibuloocular reflex dynamics during highfrequency and high-acceleration rotations of the head on body in rhesus monkey. J Neurophysiol 88:13-28. Medline

Iwasaki S, Chihara Y, Komuta Y, Ito K, Sahara Y (2008) Low-voltageactivated potassium channels underlie the regulation of intrinsic firing properties of rat vestibular ganglion cells. J Neurophysiol 100:2192-2204. CrossRef Medline

Kalluri R, Xue J, Eatock RA (2010) Ion channels set spike timing regularity of mammalian vestibular afferent neurons. J Neurophysiol 104:20342051. CrossRef Medline

Kennedy HJ (2012) New developments in understanding the mechanisms and function of spontaneous electrical activity in the developing mammalian auditory system. J Assoc Res Otolaryngol 13:437-445. CrossRef Medline

Lasker DM, Han GC, Park HJ, Minor LB (2008) Rotational responses of vestibular-nerve afferents innervating the semicircular canals in the C57BL/6 mouse. J Assoc Res Otolaryngol 9:334-348. CrossRef Medline

Li A, Xue J, Peterson EH (2008) Architecture of the mouse utricle: macular organization and hair bundle heights. J Neurophysiol 99:718-733. CrossRef Medline

Lim R, Kindig AE, Donne SW, Callister RJ, Brichta AM (2011) Potassium accumulation between type I hair cells and calyx terminals in mouse crista. Exp Brain Res 210:607-621. CrossRef Medline

Lysakowski A, Goldberg JM (1997) Regional variations in the cellular and synaptic architecture of the chinchilla cristae. J Comp Neurol 389:419443. CrossRef Medline

Lysakowski A, Minor LB, Fernández C, Goldberg JM (1995) Physiological identification of morphological distinct afferent classes innervating the cristae ampullares of the squirrel monkey. J Neurophysiol 73:1270-1281. Medline

Lysakowski A, Gaboyard-Niay S, Calin-Jageman I, Chatlani S, Price SD, Eatock RA (2011) Molecular microdomains in a sensory terminal, the vestibular calyx ending. J Neurosci 31:10101-10114. CrossRef Medline

Marcotti W, Johnson SL, Rusch A, Kros CJ (2003) Sodium and calcium currents shape action potentials in immature mouse inner hair cells. J Physiol 552:743-761. CrossRef Medline

McCue MP, Guinan JJ Jr (1994) Acoustically responsive fibers in the vestibular nerve of the cat. J Neurosci 14:6058-6070. Medline

Meredith FL, Benke TA, Rennie KJ (2012) Hyperpolarization-activated current (Ih) in vestibular calyx terminals: Characterization and role in shaping postsynaptic events. J Assoc Res Otolaryngol 13:745-758. CrossRef Medline 
Ramachandran R, Lisberger SG (2006) Transformation of vestibular signals into motor commands in the vestibuloocular reflex pathways of monkeys. J Neurophysiol 96:1061-1074. CrossRef Medline

Rennie KJ, Streeter MA (2006) Voltage-dependent currents in isolated vestibular afferent calyx terminals. J Neurophysiol 95:26-32. Medline

Ricci AJ, Kennedy HJ, Crawford AC, Fettiplace R (2005) The transduction channel filter in auditory hair cells. J Neurosci 25:7831-7839. CrossRef Medline

Rothman JS, Manis PB (2003) The roles potassium currents play in regulating the electrical activity of ventral cochlear nucleus neurons. J Neurophysiol 89:3097-3113. CrossRef Medline

Rüsch A, Eatock RA (1996) A delayed rectifier conductance in type I hair cells of the mouse utricle. J Neurophysiol 76:995-1004. Medline

Rüsch A, Eatock RA (1997) Sodium currents in hair cells of the mouse utricle. In: Diversity in auditory mechanics (Lewis ER, Long GR, Lyon RF, Steele CR, Narins PM, Hecht-Poinar E, eds), pp 549-555. Singapore: World Scientific.

Rüsch A, Lysakowski A, Eatock RA (1998) Postnatal development of type I and type II hair cells in the mouse utricle: acquisition of voltage-gated conductances and differentiated morphology. J Neurosci 18:7487-7501. Medline

Rutherford MA, Roberts WM (2006) Frequency selectivity of synaptic exocytosis in frog saccular hair cells. Proc Natl Acad Sci U S A 103:28982903. CrossRef Medline

Sadeghi SG, Chacron MJ, Taylor MC, Cullen KE (2007) Neural variability, detection thresholds, and information transmission in the vestibular system. J Neurosci 27:771-781. CrossRef Medline

Schessel DA, Ginzberg R, Highstein SM (1991) Morphophysiology of synaptic transmission between type I hair cells and vestibular primary afferents. An intracellular study employing horseradish peroxidase in the lizard, Calotes versicolor. Brain Res 544:1-16. Medline

Schnee ME, Lawton DM, Furness DN, Benke TA, Ricci AJ (2005) Auditory hair cell-afferent fiber synapses are specialized to operate at their best frequencies. Neuron 47:243-254. CrossRef Medline

Schweizer FE, Savin D, Luu C, Sultemeier DR, Hoffman LF (2009) Distribution of high-conductance calcium-activated potassium channels in rat vestibular epithelia. J Comp Neurol 517:134-145. CrossRef Medline

Sterkers O, Ferrary E, Amiel C (1988) Production of inner ear fluids. Physiological Rev 68:1083-1128. Medline

Vollrath MA, Eatock RA (2003) Time course and extent of mechanotransducer adaptation in mouse utricular hair cells: comparison with frog saccular hair cells. J Neurophysiol 90:2676-2689. CrossRef Medline

Wang LY, Fedchyshyn MJ, Yang YM (2009) Action potential evoked transmitter release in central synapses: insights from the developing calyx of Held. Mol Brain 2:36. CrossRef Medline

Weiss TF (1984) Relation of receptor potentials of cochlear hair cells to spike discharges of cochlear neurons. Annu Rev Physiol 46:247-259. CrossRef Medline

Weisz C, Glowatzki E, Fuchs P (2009) The postsynaptic function of type II cochlear afferents. Nature 461:1126-1129. CrossRef Medline

Wittig JH Jr, Parsons TD (2008) Synaptic ribbon enables temporal precision of hair cell afferent synapse by increasing the number of readily releasable vesicles: a modeling study. J Neurophysiol 100:1724-1739. CrossRef Medline

Wooltorton JR, Gaboyard S, Hurley KM, Price SD, Garcia JL, Zhong M, Lysakowski A, Eatock RA (2007) Developmental changes in two voltage-dependent sodium currents in utricular hair cells. J Neurophysiol 97:1684-1704. Medline

Yamashita M, Ohmori H (1990) Synaptic responses to mechanical stimulation in calyceal and bouton type vestibular afferents studied in an isolated preparation of semicircular canal ampullae of chicken. Exp Brain Res 80:475-488. Medline

Yamashita M, Ohmori H (1991) Synaptic bodies and vesicles in the calyx type synapse of chicken semicircular canal ampullae. Neurosci Lett 129: 43-46. CrossRef Medline 